\title{
$\beta$-Amyloid Peptides Destabilize Calcium Homeostasis and Render Human Cortical Neurons Vulnerable to Excitotoxicity
}

\author{
Mark P. Mattson, ${ }^{1}$ Bin Cheng, ${ }^{1}$ Dave Davis, ${ }^{2}$ Karin Bryant, ${ }^{2}$ Ivan Lieberburg, ${ }^{2}$ and Russell E. Rydel ${ }^{2}$ \\ ${ }^{1}$ Sanders-Brown Research Center on Aging and Department of Anatomy and Neurobiology, University of Kentucky, \\ Lexington, Kentucky 40536-0230 and ${ }^{2}$ Athena Neurosciences Inc., South San Francisco, California 94080
}

In Alzheimer's disease (AD), abnormal accumulations of $\beta$-amyloid are present in the brain and degenerating neurons exhibit cytoskeletal aberrations (neurofibrillary tangles). Roles for $\beta$-amyloid in the neuronal degeneration of AD have been suggested based on recent data obtained in rodent studies demonstrating neurotoxic actions of $\beta$-amyloid. However, the cellular mechanism of action of $\beta$-amyloid is unknown, and there is no direct information concerning the biological activity of $\beta$-amyloid in human neurons. We now report on experiments in human cerebral cortical cell cultures that tested the hypothesis that $\beta$-amyloid can destabilize neuronal calcium regulation and render neurons more vulnerable to environmental stimuli that elevate intracellular calcium levels. Synthetic $\beta$-amyloid peptides ( $\beta$ APs) corresponding to amino acids $1-38$ or 25-35 of the $\beta$-amyloid protein enhanced glutamate neurotoxicity in cortical cultures, while a peptide with a scrambled sequence was without effect. $\beta$ APs alone had no effect on neuronal survival during a $4 \mathrm{~d}$ exposure period. $\beta$ APs enhanced both kainate and NMDA neurotoxicity, indicating that the effect was not specific for a particular subtype of glutamate receptor. The effects of $\beta$ APs on excitatory amino acid (EAA)-induced neuronal degeneration were concentration dependent and required prolonged (days) exposures. The $\beta A P s$ also rendered neurons more vulnerable to calcium ionophore neurotoxicity, indicating that $\beta$ APs compromised the ability of the neurons to reduce intracellular calcium levels to normal limits. Direct measurements of intracellular calcium levels demonstrated that $\beta$ APs elevated rest levels of calcium and enhanced calcium responses to EAAs and calcium ionophore. The neurotoxicity caused by EAAs and potentiated by $\beta$ APs was dependent upon calcium influx since it did not occur in calcium-deficient culture medium. Finally, the $\beta$ APs made neurons more vulnerable to neurofibrillary tangle-like antigenic changes induced by EAAs or calcium ionophore (i.e., in-

\footnotetext{
Received May 15, 1991; revised Aug. 12, 1991; accepted Sept. 10, 1991.

We thank S. Bose, B. Rychlik, S. E. Loughran, and S. Waddell for technical assistance, P. Keim for performing the amino acid analyses, and Drs. J. Geddes and W. R. Markesbery for helpful comments. We greatly appreciate the generous contributions of antibodies from P. Davies (Alz-50) and K. S. Kosik (5E2). The help of Drs. S. Fubanks, F. Marshall, and D. Wekstein, and the University of Kentucky Internal Review Board were invaluable. Additional help was provided by B. Deasy, L. Nguyen, T. Oyler, M. Saunders, K. Shanks, and D. Wells. This work was supported by the Alzheimer's Association, the International Life Sciences Institute, and a PSP award (grants to M.P.M.) and by Athena Neurosciences, Inc. and Eli Lilly \& Company.

Correspondence should be addressed to Dr. Mark P. Mattson, Sanders-Brown Center on Aging, $800 \mathrm{~S}$. Limestone, Lexington, KY 40536-0230.

Copyright (C) 1992 Society for Neuroscience $0270-6474 / 92 / 120376-14 \$ 05.00 / 0$
}

creased staining with tau and ubiquitin antibodies). Taken together, these data suggest that $\beta$-amyloid destabilizes neuronal calcium homeostasis and thereby renders neurons more vulnerable to environmental insults.

$\beta$-Amyloid protein is the main component of the senile plaques in Alzheimer's disease (AD) (Selkoe, 1989). The $\beta$-protein corresponds to 43 amino acids in the carboxyl-terminal region of a much larger membrane-spanning precursor protein (Kang et al., 1987; Dyrks et al., 1988). The source of the $\beta$-amyloid that accumulates in $\mathrm{AD}$ is not yet clear and may be liberated from the vasculature or from brain cells (Selkoe, 1989). The mechanism resulting in the liberation of the $\beta$-protein is also not clear but is believed to involve aberrant proteolytic processing (Esch et al., 1990; Siman et al., 1990; Sisodia et al., 1990). Recent genetic studies have demonstrated a mutation in the amyloid precursor protein (APP) in at least some cases of early onset familial AD (Goate et al., 1991). On the other hand, it seems clear that late onset $\mathrm{AD}$ is a heterogeneous disorder that can probably arise from multiple environmental and/or genetic abnormalities (St George-Hyslop et al., 1990). In any case, it is clear that abnormal extracellular accumulations of $\beta$-amyloid occur in AD brain and that $\beta$-amyloid is associated with degenerated neurites and tangle-bearing neurons (Spillantini et al., $1990 \mathrm{a}, \mathrm{b})$. It has long been hypothesized that $\beta$-amyloid plays a role in the neuronal degeneration that occurs in $\mathrm{AD}$, but it is not known if and how $\beta$-amyloid might cause neurodegeneration.

A second histopathological lesion prevalent in $\mathrm{AD}$ is the neurofibrillary tangle (NFT), which consists of abnormal accumulations of cytoskeletal proteins with unique chemical and antigenic properties that allow their selective staining (see Selkoe, 1989 , for review). Neurons bearing tangles are likely to be severely impaired in their function or are dead, and tangles may therefore reflect the extent of brain damage and cognitive impairment in AD. The abnormal filaments in tangles contain the microtubule-associated protein tau (Nukina et al., 1987; Kosik et al., 1988; Love et al., 1988), as well as ubiquitin (Mori et al., 1987; Perry et al., 1987). The events leading to neurotibrillary pathology are not known, but accumulating evidence suggests that altered neuronal calcium homeostasis may be involved (Gibson and Peterson, 1987; Mattson, 1992). Thus, the results of biochemical and immunological studies suggest that tau in NFTs is excessively phosphorylated (Grundke-Iqbal et al., 1986; Ueda et al., 1990). In addition, antigenic changes similar to those seen in NFTs can be elicited by elevating intracellular calcium levels in cultured rat hippocampal (Mattson, 1990) and human cortical (Mattson et al., 1991b) neurons. Furthermore, calcium/calmodulin-dependent protein kinase II is concentrat- 
ed in neurons that are selectively vulnerable in AD (McKee et al., 1990).

Falling within the rubric of the calcium hypothesis, excitatory amino acids (EAAs) have received considerable attention and are strongly implicated in an array of neurodegenerative conditions (Maragos et al., 1987; Choi, 1988; Greenamyre and Young, 1989; Mattson, 1991). Neurons that are not able to maintain intracellular calcium levels within certain limits are at risk, and it is well established that EAA neurotoxicity is mediated largely by a loss of calcium homeostasis resulting in sustained elevations in intracellular calcium (Choi, 1987; Mattson et al., 1988, 1989a, 1991a). There is a close relationship between a neuron's vulnerability in disorders such as Huntington's disease, stroke, and AD and that neuron's vulnerability to EAA-induced neuronal degeneration in vivo (Coyle et al., 1981; Beal et al., 1986) and in vitro (Mattson and Kater, 1989). In addition, many of the cytoskeletal alterations seen in AD NFTs can be elicited by EAAs and experimentally induced calcium influx in cultured rat hippocampal (Mattson, 1990) and human cerebral cortical (Mattson et al., 1991b) neurons. Sustained elevations in intracellular calcium levels caused a reduction in microtubules, the accumulation of straight filaments, and increased immunoreactivity toward antibodies that recognize tau and ubiquitin in NFTs. Apparently, calcium-activated kinases cause excess phosphorylation of tau (GrundkeIqbal et al., 1986; Ueda et al., 1990), and such phosphorylation may be an important event in the cytoskeletal pathology of AD.

Several recent studies have provided evidence that $\beta$-amyloid peptides ( $\beta \mathrm{APs})$ are neurotoxic toward rodent central neurons. Pheochromocytoma ( $\mathrm{PC1}$ ) cells transfected with portions of the gene for the APP released a peptide derived from the APP into the culture medium that was neurotoxic toward cultured hippocampal neurons (Yankner et al., 1989). Yankner et al. (1990) recently reported that $\beta$ APs were toxic toward differentiated rat hippocampal neurons and that the neurotoxic activity resided within amino acids $25-35$ of the $\beta$-protein. On the other hand, Koh et al. (1990a) reported that $\beta$-amyloid alone was not neurotoxic toward cultured mouse cortical neurons, but did make the neurons more vulnerable to EAA neurotoxicity. The latter finding suggested the possibility of a link between the EAA/calcium hypothesis and the amyloid hypothesis of $\mathrm{AD}$. If $\beta$-amyloid does in fact make neurons more vulnerable to EAA neurotoxicity, then it might be expected that neurons receiving a relatively high level of glutamatergic input and encountering $\beta$-amyloid might be at risk in AD. However, all of this previous work was done in rodent systems, and there is no direct information available on possible neurotoxic actions of $\beta$-amyloid in humans. This point is particularly salient since rodents do not develop $\beta$-amyloid plaques or NFTs, and it is therefore not clear how the data obtained in rodent systems pertain to the human disease. We now report that human cortical neurons exposed to $\beta$ APs are more vulnerable to EAA- and calcium ionophore-induced calcium influx, neurotoxicity, and AD-like antigenic alterations. The data indicate that $\beta$-amyloid destabilizes neuronal calcium homeostasis.

\section{Materials and Methods}

Cell culture. Cultures were established from cryopreserved stocks of dissociated fetal human cerebral cortical cells (14-16 weeks gestation) as detailed in our previous report (Mattson and Rychlik, 1990). The protocol for obtaining postmortem fetal neural tissue complied with all federal guidelines for fetal research, with the Uniformed Anatomical
Gift Act, and with guidelines established by the Medical Institutional Review Board of the University of Kentucky. Following rapid thawing of the frozen cells, cultures were established directly from the cell suspensions. Cells were seeded into polylysine-coated $35 \mathrm{~mm}$ plastic culture dishes containing $2 \mathrm{ml}$ of medium to obtain a cell density of 80-120/ $\mathrm{mm}^{2}$ of culture surface. Culture maintenance medium was Eagle's Minimum Essential Medium (glutamate free and containing $1.8 \mathrm{~mm} \mathrm{CaCl}_{2}$ ) supplemented with $10 \mathrm{~mm}$ sodium bicarbonate, $40 \mathrm{~mm}$ glucose, $1 \mathrm{~mm}$ L-glutamine, $20 \mathrm{~mm} \mathrm{KCl}, 1 \mathrm{~mm}$ sodium pyruvate, and $10 \%$ (v/v) heatinactivated fetal bovine serum (Sigma, lot 107F-0607). Normal levels of glutamate in serum average 100-150 $\mu \mathrm{M}$ (Jones and Gilligan, 1983), and it is therefore estimated that the culture maintenance medium initially contained $10-15 \mu \mathrm{M}$ glutamate. After a 12-16 hr incubation period to allow cell attachment, cultures were rinsed once with fresh medium and then $0.8 \mathrm{ml}$ of medium was added. Cultures were maintained in a humidified atmosphere $\left(5 \% \mathrm{CO}_{2}, 95 \%\right.$ room air) at $36-37^{\circ} \mathrm{C}$.

Analysis of neuronal survival. The cell types constituting the human fetal cortical cultures have been characterized in our previous study (Mattson and Rychlik, 1990). Essentially all neurons in these cortical cultures elaborate one long process that is axon-like by several criteria including its complement of cytoskeletal proteins. The glia in these cultures are type I astrocytes based upon their morphology and content of glial fibrillary acidic protein. In the present study, experiments were done in cells that had been in culture 21-28 d. Cells in premarked regions (four areas of approximately $0.5 \mathrm{~mm}^{2}$ in each culture; 80-140 cells/ dish) of the cultures were examined by phase-contrast light microscopy at an initial time point, and at designated time points following experimental treatment. Normal "healthy" neurons were characterized by a soma that was smooth and round to oval in shape, and possessed neurites with a relatively uniform diameter and a smooth appearance. Degenerating neurons were characterized by a rough appearance and irregular shape to the soma, neurite fragmentation and "beading," and finally cell lysis or detachment from the substrate. Neurons were considered nonviable if they exhibited the aformentioned morphological changes or if they were absent. Our previous studies showed that neurons with fragmented neurites and somal vacuolation either stain with trypan blue or propidium iodide and are therefore nonviable (Mattson et al., 1988; M. P. Mattson, B. Cheng, D. Davis, K. Bryant, I. Lieberburg, and R. E. Rydel, unpublished observations), or exhibit antigenic changes similar to those seen in neurofibrillary tangles in Alzheimer's disease (Mattson, 1990). Unless otherwise stated, all experiments in which cell survival was assessed were done in cultures containing the normal culture maintenance medium that contained $1.8 \mathrm{~mm} \mathrm{Ca}^{2+}$. All data are reported as the mean and SEM. Statistical comparisons were made using Student's $t$ test.

Synthetic $\beta$-amyloid peptides. Synthetic $\beta$ AP 1-38 was purchased from Bachem Inc. (Torrance, CA). All other synthetic $\beta$ APs were made on an Applied Biosystems model 430A peptide synthesizer (Foster City, CA) using modified double couple capping cycles for each amino acid addition. All chemicals, reagents, and boc amino acids were purchased from Applied Biosystems, with the exception of dichloromethane and $N, N$-dimethylformamide, which were Fisher Biotech grade. Side chainprotected amino acids were coupled following preactivation to the symmetric anhydride using 0.5 equivalents of $N, N$-dicyclohexylcarbodiimide in dichloromethane. Glutamine and asparagine were preactivated to their respective 1-hydroxybenzotriazole (HOBT) esters using 1 equivalent of dicyclohexylcarbodiimide and 1 equivalent of HOBT in dimethylformamide. Capping of any uncoupled amine with $10 \%$ acetic anhydride in dichloromethane followed the recoupling step for each amino acid addition. The capping protocol was used to minimize synthesis of deletion peptides, which are often difficult to separate from the target peptide. The boc protecting group on the amino acid $\alpha$-amine is removed with $50 \%$ trifluoroacetic acid (TFA) in dichloromethane.

Amino acid side chain protection was as follows: Arg(tosyl), Asp(Bzl), Cys(4-MeBzl), Glu(Bzl), His(CBZ) or His(BOM), Lys(CL-Z), Ser(OBzl), $\mathrm{Thr}(\mathrm{OBzl})$, and $\operatorname{Tyr}(\mathrm{Br}-\mathrm{Z})$. All other amino acids were used with no further side chain protection [(Bzl), benzyl; (4-MeBzl), 4-methylbenzyl; (CBZ), carbobenzyoxy; (BOM), butyloxymethyl; (CL-Z), chlorobenzyloxycarbonyl; (OBzl), O-benzyl; (Br-Z), bromobenzyloxycarbonyl].

Peptides with $C$-terminal amides were synthesized on a $p$-methylbenzhydrilamine (MBHA) resin. The C-terminal amino acid was coupled to the solid support using the same protocol as that used from amino acid couplings. The fully protected peptide resin was deprotected and cleaved from the resin by reacting with anhydrous hydrogen fluoride (HF) at $0^{\circ} \mathrm{C}$ for $1 \mathrm{hr}$. The MBHA resin yields the peptide amide after 
treatment with HF. Peptides with C-terminal carboxylic acids were synthesized on phenylacetamidomethyl (PAM) resins, which gave the desired peptide acid following HF treatment. In this case, the starting resin was purchased with the C-terminal boc amino acid attached to the solid support. Following HF treatment, each peptide was extracted from the resin in $2 \mathrm{~N}$ acetic acid and lyophilized. The crude peptide was then purified using preparative reverse-phase HPLC on a Vydac C18, $330 \AA$ A $10 \mu \mathrm{m}$ column $(2.2 \mathrm{~cm}$ i.d. $\times 25 \mathrm{~cm})$. Our solvent system of choice is $0.1 \%$ TFA/ $/ \mathrm{H}_{2} \mathrm{O}$ (A buffer) and $0.1 \%$ TFA/ $/ \mathrm{CH}_{3} \mathrm{CN}$ (B buffer) as the mobile phase. Typically, the peptide was loaded onto the column in $2 \% \mathrm{~B}$ buffer at $4 \mathrm{ml} / \mathrm{min}$ and eluted using a linear gradient of $2-60 \%$ $B$ buffer over $174 \mathrm{~min}$. Each peptide was subjected to amino acid analysis and analyzed on analytical reverse-phase HPLC. If necessary, structural integrity of a peptide was confirmed by both protein sequence analysis and mass spectrophotometric analysis.

Experimental treatments. Stock solutions of $\beta$ APs were prepared by dissolving the peptides at a concentration of $0.5-1.0 \mathrm{~mm}$ in water or 1 mM in dimethylsulfoxide (DMSO); the stocks were stored as aliquots at $-20^{\circ} \mathrm{C}$ until used. Solubility of $\beta$-amyloid $1-38,25-35$, and scrambled 25-35 peptides was determined by amino acid analysis before and after centrifugation at $100,000 \times g$. While this method cannot distinguish between $\beta$-amyloid monomers and small soluble aggregates, it clearly distinguishes between soluble forms and large aggregate precipitates. Stock solutions prepared in DMSO were completely soluble at $1 \mathrm{~mm}$ and maintained their solubility when diluted into Hank's balanced salt solution (HBSS; GIBCO). Stock solutions dissolved in water were soluble at $1 \mathrm{~mm}$ but formed large aggregate precipitates when diluted into HBSS. HBSS was used as an indication of the solubility of $\beta$ APs in tissue culture medium. The amino acid supplements in tissue culture medium preclude the use of amino acid analysis for protein determinations. The sequences of peptides used were $\beta$-amyloid $1-38$, $\mathrm{NH}_{2}$-DAEFRHDSGYEVHHQKLVFFAEDVGSNKGAIIGLMVGG$\mathrm{COOH} ; \beta$-amyloid $25-35, \mathrm{NH}_{2}$-GSNKGAIIGLM-COOH; and $\beta$-amyloid 25-35scrambled, $\mathrm{NH}_{2}$-IMLKGNGASIG-COOH. Unless stated otherwise, peptides with a free carboxyl terminus were used. Peptides in DMSO were diluted at least 100 -fold in culture medium so that the concentration of DMSO in culture medium was never greater than $1 \%$ (DMSO alone was added to cultures not exposed to a peptide). L-Glutamate, kainate, $N$-methyl-D-aspartate (NMDA), D-glutamylglycine (DGG), and D,L-2-amino-5-phosphonovaleric acid (APV) were prepared as $20-500 \times$ concentrated stocks in saline, while calcium ionophore A23187 was prepared as a $500 \times$ concentrated stock in DMSO (all of these agents were from Sigma). Calcium-deficient medium consisted of HBSS containing no added calcium, $1 \mathrm{~mm} \mathrm{MgCl}_{2}, 1 \mathrm{~mm}$ L-glutamine, $15 \mathrm{~mm}$ sodium bicarbonate, $5 \mathrm{~mm}$ HEPES, $1 \mathrm{~mm}$ pyurvate, and $40 \mathrm{~mm}$ glucose (pH 7.2). All treatments were begun in cells that had been in culture $21-24 \mathrm{~d}$, since during this time period the neurons are known to exhibit calcium responses to glutamate, but are not highly vulnerable to glutamate neurotoxicity (Mattson et al., 1991b).

Fura-2 measurements of intracellular calcium levels. Procedures for measuring intracellular free $\mathrm{Ca}^{2+}$ levels in cultured neurons using fura-2 are detailed in our previous studies (Mattson et al., 1989a,b, 1991a). Cells were loaded at $37^{\circ} \mathrm{C}$ for $30-45 \mathrm{~min}$ with $4-6 \mu \mathrm{M}$ concentrations of the acetoxymethyl ester form of fura-2 (Molecular Probes). The loaded cells were then washed with fresh medium and incubated for at least $1 \mathrm{hr}$ prior to imaging. Prior to imaging, the normal culture medium was replaced with HBSS containing $2 \mathrm{mM} \mathrm{CaCl}, 1 \mathrm{mM} \mathrm{MgCl}_{2}$, and $1 \%$ glucose.

Images were obtained with a Quantex intensified $\mathrm{CCD}$ camera. A Quantex imaging system with QFM software was used to acquire and process the images. This system was coupled to a Nikon Diaphot microscope, and a fluoro $40 \times$, n.a. 1.3 fluorescence objective was used. Intracellular $\mathrm{Ca}^{2+}$ levels were determined from the ratio of the fluorescence emission using two different excitation wavelengths $(350 \mathrm{~nm}$ and $380 \mathrm{~nm}$ ). Background fluorescence at each wavelength (background images were taken from regions of the culture dish not containing cells) was subtracted from the cell image at that wavelength. The fluorescence of fura- 2 increases at $350 \mathrm{~nm}$ excitation with calcium binding and decreases at $380 \mathrm{~nm}$ with calcium binding (Grynkiewicz et al., 1985). The ratio of fluorescence in digitized images taken at 350 and $380 \mathrm{~nm}$ excitation therefore is a direct indicator of intracellular calcium concentrations. The system was calibrated according to the procedures of Grynkiewicz et al. (1985). Statistical comparisons used Student's $t$ test.

Immunocytochemistry. For all comparisons, cortical cell cultures were established, maintained, treated, and processed in parallel. Following exposure to treatments, cells were fixed for $20-30 \mathrm{~min}$ in either $4 \%$ paraformaldehyde in PBS for staining with Alz-50 and ubiquitin antibodies, or in PLP fixative for staining with antibody 5E2 (PLP contained $2 \%$ paraformaldehyde, $100 \mathrm{~mm} \mathrm{D}, \mathrm{L}-\mathrm{lysine}$, and $10 \mathrm{~mm}$ sodium $m$-periodate). Fixed cultures were exposed for $5 \mathrm{~min}$ to a $0.2 \%$ solution of Triton X-100 in PBS and were processed using a primary antibody and appropriate Vectastain $\mathrm{ABC}$ avidin-biotin-peroxidase kits with diaminobenzidine tetrahydrochloride as a substrate. Primary antibodies included Alz-50, a monoclonal raised against Alzheimer's disease neurofibrillary tangles (Wolozin et al., 1986); 5E2, a monoclonal raised against fetal human tau (Kosik et al., 1988); and a polyclonal rabbit antiserum against ubiquitin (Sigma). Antibody dilutions were 5E2, 1 400; Alz-50, 1:30; and anti-ubiquitin, 1:500. Negative controls consisted of substituting nonimmune serum for the primary antibodies. In addition, cell specificity of the staining provided an important criterion for judging the specificity of staining (e.g., tau immunostaining was present in neurons but not in glia). The same exposure conditions were used to photograph all cells, and bright-field prints were exposed for the same time periods. For semiquantitative comparisons, neuronal staining intensities were scored on a scale from 0 to $3(0$, no staining; 1 , low; 2 , moderate; 3 , intense). A total of 300 neurons in three separate cultures (100 neurons/culture) were scored without knowledge of the treatment history of the cultures.

\section{Results}

$\beta A P$ s enhance $E A A$ neurotoxicity. Our past work demonstrated that cultured human fetal cerebral cortical neurons become sensitive to EAA-induced calcium influx and neurotoxicity mediated by NMDA and kainate receptors during a period of 3-5 weeks in culture (Mattson et al., 1991a). All data reported here were from experiments in cells that had been in culture for 21$28 \mathrm{~d}$; treatments wcrc added to cultures on days 21-24. Synthetic $\beta$ APs corresponding to amino acids $1-38$ or $25-35$ of the $\beta$-amyloid protein at concentrations of up to $80 \mu \mathrm{M}$ (diluted from aqueous peptide stocks) by themselves had no significant effect on neuronal survival during a $4 \mathrm{~d}$ exposure period (Figs. 1,2 ). Glutamate caused a dose-dependent reduction in neuronal survival during a $4 \mathrm{~d}$ exposure period with 1 and $2 \mathrm{~mm}$ glutamate, causing $20 \%$ and $60 \%$ of the neurons to degenerate (Fig. $1 A$ ). When neurons were exposed to increasing concentrations of glutamate and $\beta$ AP $1-38$ or $25-35(20-80 \mu \mathrm{M})$, neuronal survival was significantly reduced relative to cultures incubated in the presence of glutamate alone. In effect, the peptides shifted the dose-response curve for glutamate neurotoxicity to the left, with the estimated concentrations of glutamate required to kill $50 \%$ of the neurons being glutamate alone, $1.8 \mathrm{~mm}$; glutamate plus $\beta$ AP 1-38, $0.75 \mathrm{~mm}$; and glutamate plus $\beta$ AP $25-35,0.4$ mM. The enhancement of glutamate neurotoxicity was specific for the $\beta$ APs since a peptide with the same amino acid composition as $\beta$ AP $25-35$, but with a scrambled sequence, did not alter glutamate neurotoxicity (Fig. $1 A$ ). The enhancement of glutamate neurotoxicity by $\beta$ APs was dependent upon the concentration of the peptides added to the cultures (Fig. $1 B$ ). Concentrations of $\beta$ APs $1-38$ and $25-35$ of $10 \mu \mathrm{M}$ or less had little effect on the number of neurons killed by 1 mm glutamate. With increasing concentrations of the $\beta$ APs from 20 to $80 \mu \mathrm{M}$, there was a progressive enhancement of glutamate neurotoxicity. $\beta A P$ 25-35 was more potent than 1-38 in enhancing glutamate neurotoxicity. Enhancement of glutamate neurotoxicity was also seen with $\beta$ APs $25-35 \mathrm{CONH}_{2}(20 \mu \mathrm{M}$ or greater), indicating that this action of the peptide was not dependent upon a free carboxyl terminus (data not shown).

Phase-contrast micrographs in Figure 2 show fields of cultured human fetal cortical neurons before and after exposure to $\beta \mathrm{AP}$ 1-38 alone, glutamate plus scrambled $\beta \mathrm{AP}$, or glutamate plus 
$\beta$ AP $1-38$. The neuronal degeneration induced by glutamate and enhanced by the $\beta$ APs was characterized by swelling and vacuolation of the cell bodies, neurite fragmentation, and ultimately cell lysis (Fig. 2C).

The time course of neuronal degeneration in cortical cultures exposed to $\beta A P$ s and glutamate is shown in Figure 3. Very little neuronal death occurred in cultures exposed to $1 \mathrm{mM}$ glutamate or glutamate plus a $\beta$ AP during the first $24 \mathrm{hr}$ of exposure. After $1 \mathrm{~d}$ of exposure, a small (approximately 10\%) neuronal loss occurred in cultures exposed to glutamate, and this attrition was significantly enhanced by $\beta$ APs $1-38$ and $25-35$. In one experiment, we exposed the neurons to the $\beta$ APs for different time periods prior to the addition of glutamate, in order to determine whether such pretreatment would accelerate neuronal degeneration. Cultures were exposed to BAP 1-38 (40 $\mu \mathrm{M}) 48$ or 24 $\mathrm{hr}$ prior to the time of addition of $1 \mathrm{~mm}$ glutamate, or at the time of addition of glutamate, and neuronal survival was assessed $24 \mathrm{hr}$ following exposure to glutamate. Neuronal survival values were $48 \mathrm{hr} \beta \mathrm{AP}$ pretreatment, $41 \pm 5.3 \% ; 24 \mathrm{hr} \beta \mathrm{AP}$ pretreatment, $63 \pm 3.1 \%$; and $0 \mathrm{hr} \beta \mathrm{AP}$ treatment, $84 \pm 4.1 \%$ $[n=4$ separate cultures; survival was significantly less in cultures pretreated with the $\beta$ AP $(p<0.05-0.01)]$.

Since $\beta$ APs $1-38$ and $25-35$ were relatively insoluble in buffered salt solutions (see Materials and Methods), it was of interest to determine whether the dose-response curve for enhancement of glutamate neurotoxicity would be affected when the peptides were dissolved in a more hydrophobic solution. Amino acid analysis before and after centrifugation at 100,000 $\times g$ demonstrated that $\beta$ APs maintained their solubility when prepared in DMSO and then diluted into HBSS (data not shown). When peptide stocks were prepared in DMSO and then diluted in the culture medium, the dose-response curve for enhancement of glutamate neurotoxicity was shifted to the left by nearly 2 orders of magnitude (Fig. 4, as compared to Fig. 1B).

$\beta A P s$ alone had no significant effect on astrocyte numbers during a $4 \mathrm{~d}$ exposure period. Astrocyte nuclei in defined microscope fields were counted immediately prior to, and $4 \mathrm{~d}$ following, exposure to $\beta$ AP $1-38$ or $25-35$ ( $5 \mu \mathrm{M}$ from DMSO stock). Values in the different conditions (percentage of initial number of astrocytes prior to treatment) were control $(0.5 \%$ DMSO), $121 \pm 5.3$; $\beta$ AP $1-38,130 \pm 11.2$; and $\beta$ AP $25-35$, $140 \pm 6.1$ ( $n=4$ separate fields). Astrocyte numbers in cultures exposed to both a $\beta$ AP $(5 \mu \mathrm{M})$ and glutamate $(1 \mathrm{mM})$ were not significantly different than in cultures treated with glutamate alone (percentage of the initial number of astrocytes: glutamate alone, $92 \pm 8.3 ; \beta$ AP $1-38$ plus glutamate, $92 \pm 7.3$; $\beta$ AP $25-$ 35 plus glutamate, $95 \pm 6.3$ ). These data arc consistent with a previous report that showed no toxicity of $\beta$ APs toward cultured rat astrocytes (Yankner et al., 1990) and indicate that the neurotoxic actions of $\beta$ APs are specific for neurons.

$\beta A P s$ enhance both kainate and NMDA neurotoxicities. Two different glutamate receptor agonists were employed in order to determine whether the enhancement of glutamate neurotoxicity was specific for a particular type of EAA receptor. Neuronal survival following exposure to kainate $(200 \mu \mathrm{M})$ or NMDA (500 $\mu \mathrm{M})$ was significantly less in cultures maintained in the presence of $\beta \mathrm{AP} 1-38$ or $25-35$ than in cultures maintained in the absence of peptide or in the presence of scrambled peptide (Fig. 5). Whereas approximately $60 \%$ of the neurons in control cultures survived a $2 \mathrm{~d}$ exposure to kainate, less than $10 \%$ of the neurons survived when cotreated with a $\beta$ AP (Fig. 5). NMDA alone or together with scrambled peptide caused only minimal neuronal
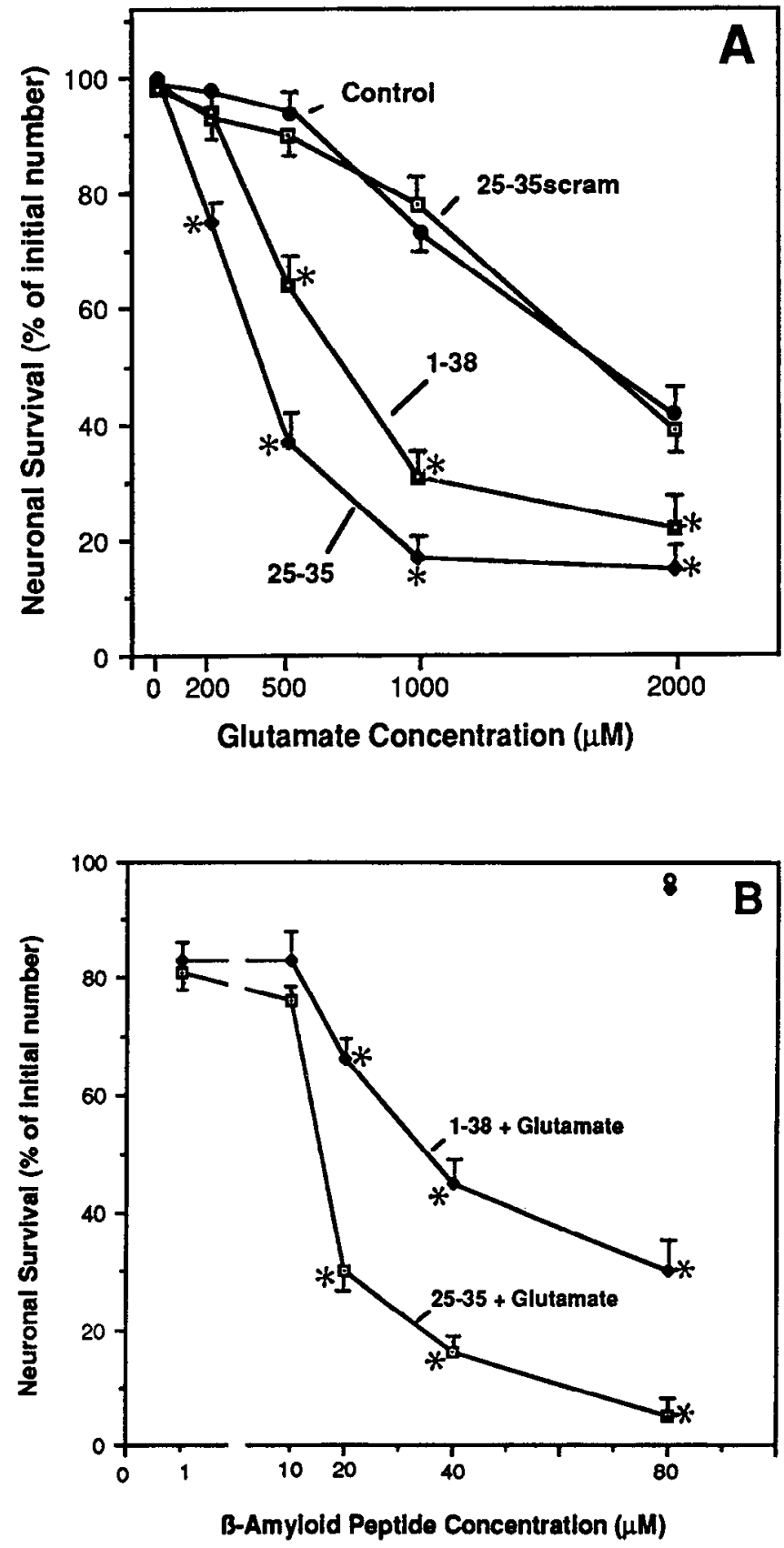

Figure 1. $\beta$ APs enhance glutamate neurotoxicity in human cortical cell cultures. $A$. Cultures were exposed for $4 \mathrm{~d}$ to the indicated concentrations of glutamate and either no peptide (Control) or one of the following peptides (diluted from aqueous stocks): $\beta$ AP $25-35$ scrambled $(40 \mu \mathrm{M}), \beta$-amyloid $25-35(20 \mu \mathrm{M})$, or $\beta$ AP $1-38(40 \mu \mathrm{M})$. The percentage of neurons that survived the $4 \mathrm{~d}$ exposure period was determined, and values represent the mean and SEM of determinations made in four separate cultures. ${ }^{*}, p<0.05-0.001$ compared to corresponding values for control cultures and cultures treated with $\beta$ AP 25-35 scrambled. $B$, Concentration dependence of $\beta A P$ enhancement of glutamate neurotoxicity. Cultures were exposed for $4 \mathrm{~d}$ to the indicated concentrations of $\beta A P$ 1-38 or $25-35$ (diluted from aqueous stocks) plus $1 \mathrm{~mm}$ glutamate. The percentage of neurons that survived the exposure period was determined and values represent the mean and SEM of determinations made in four separate cultures. Open circle, treatment with $\beta$ AP 1-38 alone; diamond, treatment with $\beta$ AP $25-35$ alone. ${ }^{*}, p<0.05-$ 0.001 compared to values for cultures treated with 1 or $10 \mu \mathrm{M} \beta$-peptide plus glutamate. 

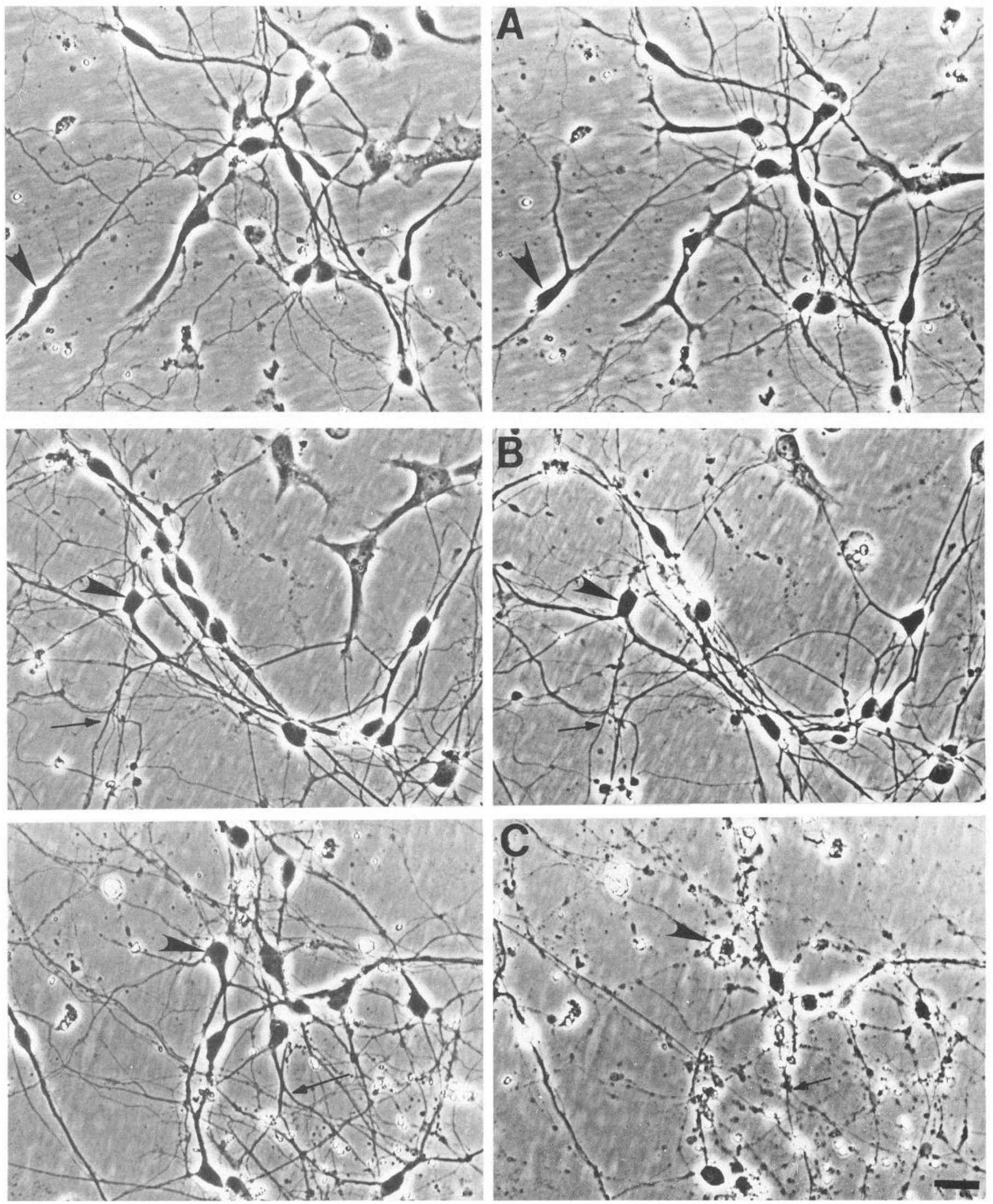

Figure 2. $\quad \beta$-Amyloid renders human cortical neurons more vulnerable to glutamate toxicity: phase-contrast micrographs of fields of cultured human cortical cells prior to (left) and $4 \mathrm{~d}$ following (right) exposure to the following treatments: $A, 40 \mu \mathrm{M} \beta \mathrm{AP} 1-38 ; B, 500 \mu \mathrm{M}$ glutamate plus $40 \mu \mathrm{M} \beta \mathrm{AP} 25-35$ scrambled; $C$, $500 \mu \mathrm{M}$ glutamate plus $40 \mu \mathrm{M} \beta \mathrm{AP} 1-38$ ( $\beta$ APs were diluted from aqueous stocks). Note that essentially all neurons appear healthy (e.g., arrowheads) before and after exposure to $\beta$ AP 1-38 alone $(A)$. The majority of neurons also survived the $4 \mathrm{~d}$ exposure to glutamate in the presence of scrambled $\beta \mathrm{AP}$ (e.g., arrowheads in $B$ ). In contrast, the vast majority of neurons degenerated during the $4 \mathrm{~d}$ exposure to glutamate plus $\beta$ AP $1-38$. Scale bar, $10 \mu \mathrm{m}$. 

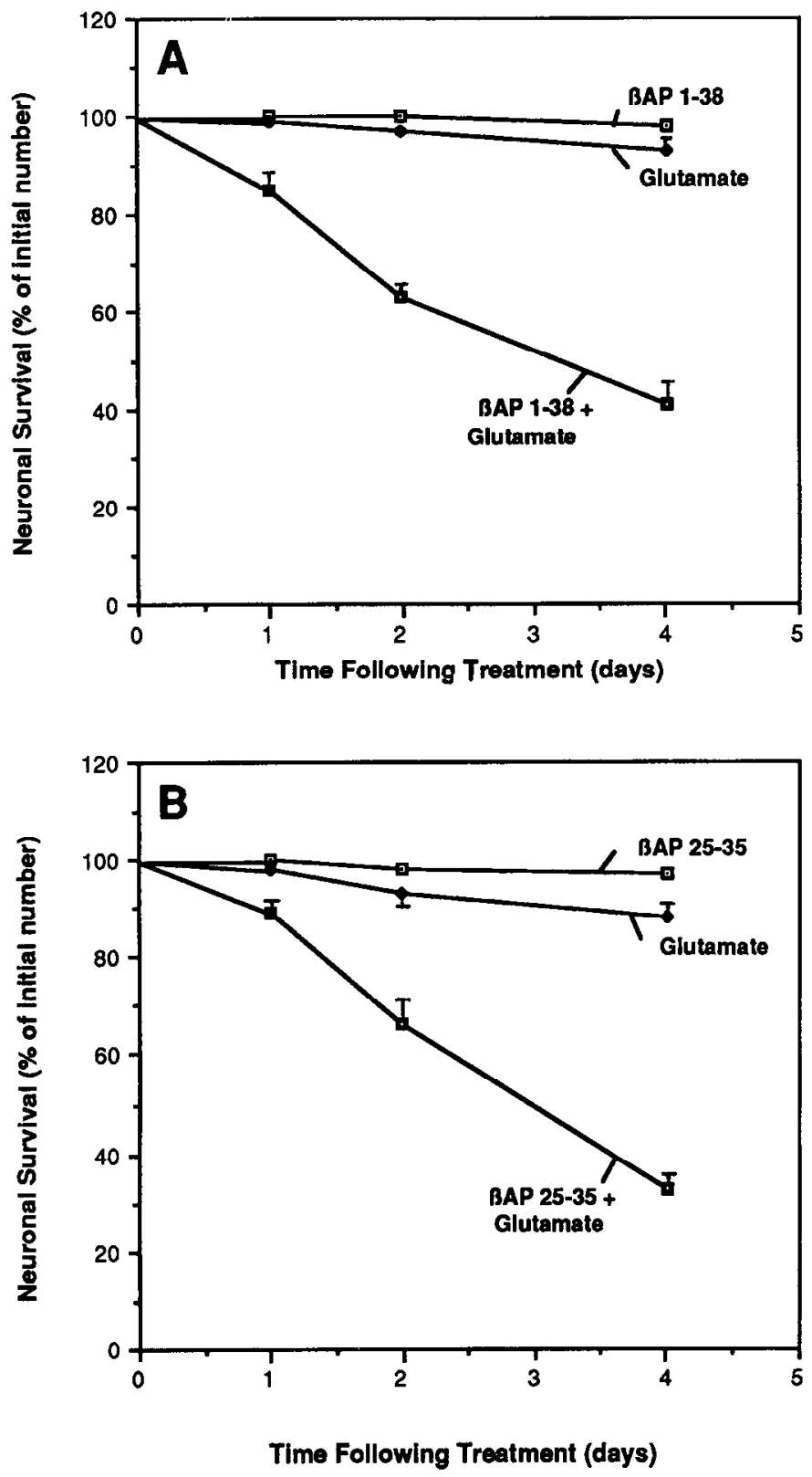

Figure 3. Time course of neuronal degeneration in cultures treated with $\beta$ APs and glutamate. Cortical cultures were exposed to $\beta$ AP (40 $\mu \mathrm{M} 1-38$ or $20 \mu \mathrm{M} 25-35$ ) with or without glutamate (1 mM) at time 0 as indicated ( $\beta$ APs were diluted from aqueous stocks). Neuronal survival was determined 1,2 , and $4 \mathrm{~d}$ following treatment. Values are the mean and SEM (four separate cultures).

damage, while $60-80 \%$ of the neurons were destroyed in cultures cotreated with NMDA and a $\beta$ AP (Fig. 5). Kainate and NMDA were more potent than glutamate in inducing neuronal death (compare Fig. 5 with Figs. $1 A, 3$ ). These data are consistent with similar studies that examined the neurotoxic potencies of these different agonists (see Coyle et al., 1981; Choi, 1988; Mattson et al., 1988). These data indicate that the EAA neurotoxicityenhancing effects of $\beta$ APs in human cortical neurons involve the normal receptor-mediated mechanism and are not specific for a particular type of glutamate receptor.

In order to verify that the enhancement of EAA neurotoxicity observed with $\beta$ APs did in fact involve the normal glutamate

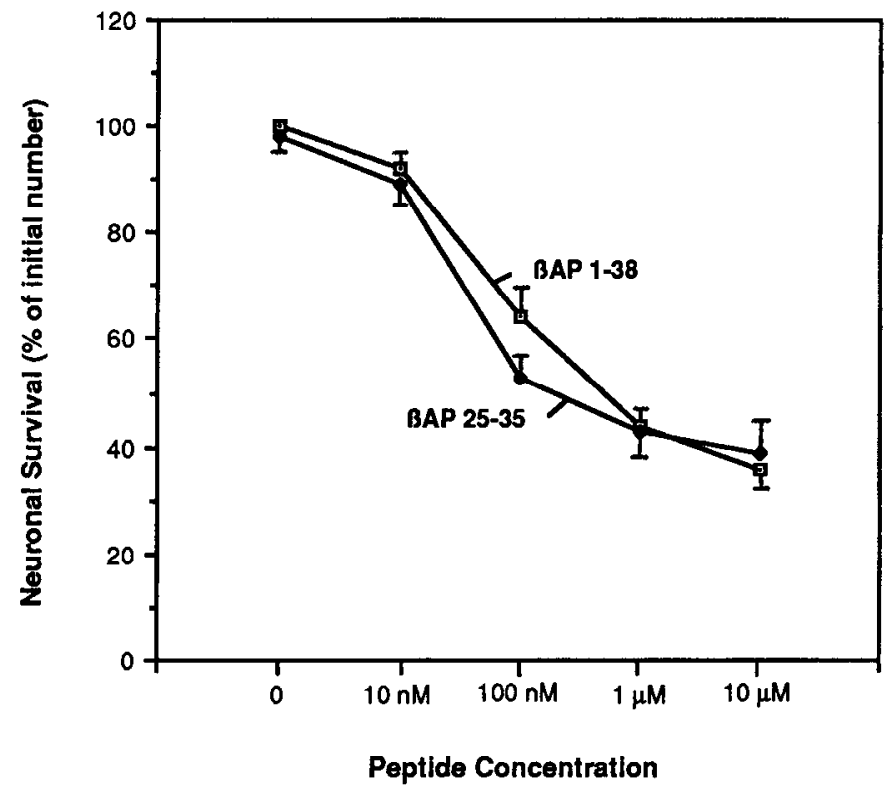

Figure 4. Enhanced potency of solubilized $\beta$ APs. Cortical cultures were maintained for $3 \mathrm{~d}$ in the presence of the indicated concentrations of $\beta A P s$ that were prepared as stocks $(\geq 100 x)$ in DMSO (DMSO alone at a final concentration of $0.5 \%$ was added to cultures receiving no peptide). The cells were then exposed to $1 \mathrm{~mm}$ glutamate, and neuronal survival was assessed $24 \mathrm{hr}$ later. Values are expressed as percentages of the initial number of viable neurons present prior to exposure to glutamate (mean and SEM; $n=3$ separate cultures).

receptor-mediated excitotoxic pathway, we determined if the

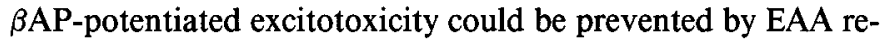
ceptor antagonists (Fig. 6). The NMDA receptor-specific antagonist APV $(500 \mu \mathrm{M})$ prevented the neuronal death that normally occurred in cultures exposed to NMDA plus $\beta$ AP 1-38 or 25-35. Similarly, $\beta$ AP-potentiated kainate neurotoxicity was completely abolished by $500 \mu \mathrm{M}$ DGG.

$\beta A P S$ enhance $E A A$-induced elevations in intracellular calcium. EAA neurotoxicity is mediated largely by sustained elevations in intracellular calcium levels (Choi, 1987; Mattson et al., 1988, 1991a). It was therefore of interest to determine whether $\beta$ APs affected intracellular calcium levels in the cultured cortical neurons. Intracellular free calcium levels were quantified using the calcium indicator dye fura-2. These experiments used water-solubilized $\beta$ AP stocks. In cultures treated with $40 \mu \mathrm{M}$ $\beta$ AP 25-35 scrambled peptide for $2 \mathrm{~d}$, intracellular calcium levels were $79 \pm 2.6 \mathrm{nM}$ (Fig. 7), a level not significantly different than that in untreated control cultures $(75 \pm 1.8 \mathrm{nM} ; n=8)$. Intracellular calcium levels in cortical neurons exposed to either $40 \mu \mathrm{M} \beta \mathrm{AP} 1-38$ or $20 \mu \mathrm{M} \beta \mathrm{AP} 25-35$ for $2 \mathrm{~d}$ were elevated $10-15 \%$ relative to levels in control cultures, but the difference was not significant. Exposure to $500 \mu \mathrm{M}$ glutamate for $2 \mathrm{~d}$ resulted in no significant change in intraneuronal calcium levels relative to control cultures (Fig. 7). Cotreatment of neurons for $2 \mathrm{~d}$ with glutamate and $\beta$ AP $1-38$ or $25-35$ resulted in a highly significant threefold elevation in intracellular calcium levels. $\beta A P ~ 25-35 \mathrm{NH}_{2}(40 \mu \mathrm{M})$ also made neurons vulnerable to glutamate-induced rises in intracellular calcium levels (data not shown).

In order to determine whether the elevations in intraneuronal calcium levels seen in cultures cotreated with $\beta$ APs and glutamate actually mediated the neuronal degeneration, we incubated 


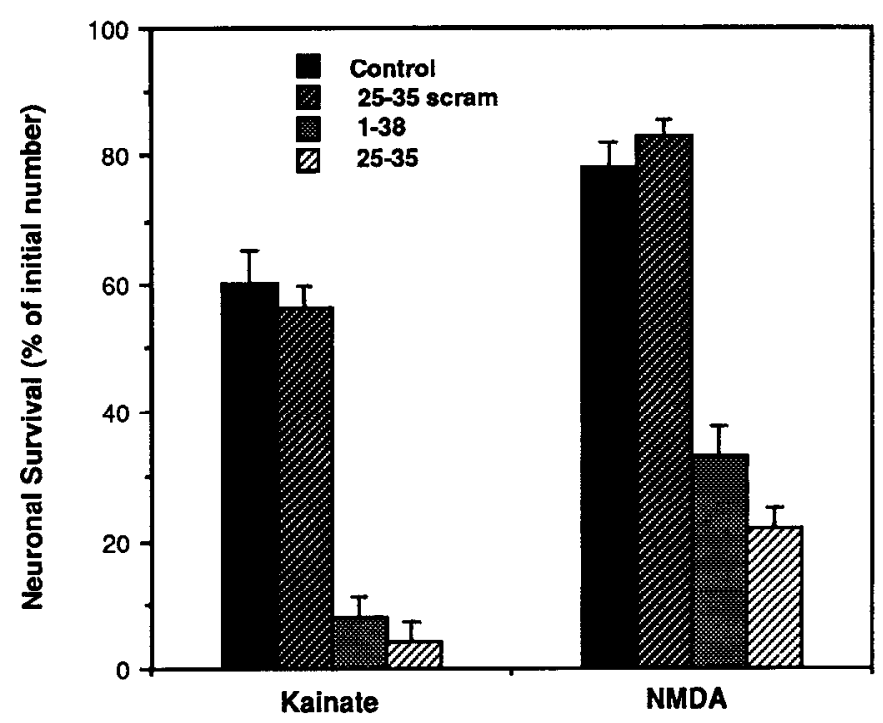

Figure 5. $\beta A P$ s enhance kainate and NMDA ncurotoxicitics. Cultures were exposed for $2 \mathrm{~d}$ to either $200 \mu \mathrm{M}$ kainate or $500 \mu \mathrm{M}$ NMDA, plus $40 \mu \mathrm{M}$ of the indicated $\beta$ APs (25-35scrambled, 1-38, and 25-35; diluted from aqueous stocks), or no peptide (Control). The percentage of neurons that survived the exposure period was determined, and values represent the mean and SEM of determinations made in four separate cultures. Values for Control and 25-35scrambled-treated cultures were significantly greater than values for cultures treated with $\beta$ APs $1-38$ or $25-35(p<0.01-0.001)$.

cells in medium that lacked calcium. Cultures were pretreated with $\beta$ APs for $2 \mathrm{~d}$, followed by a $24 \mathrm{hr}$ exposure to $500 \mu \mathrm{M}$ glutamate in medium that contained $2 \mathrm{~mm}$ calcium or no added calcium. A $24 \mathrm{hr}$ exposure period to the calcium-deficient me-

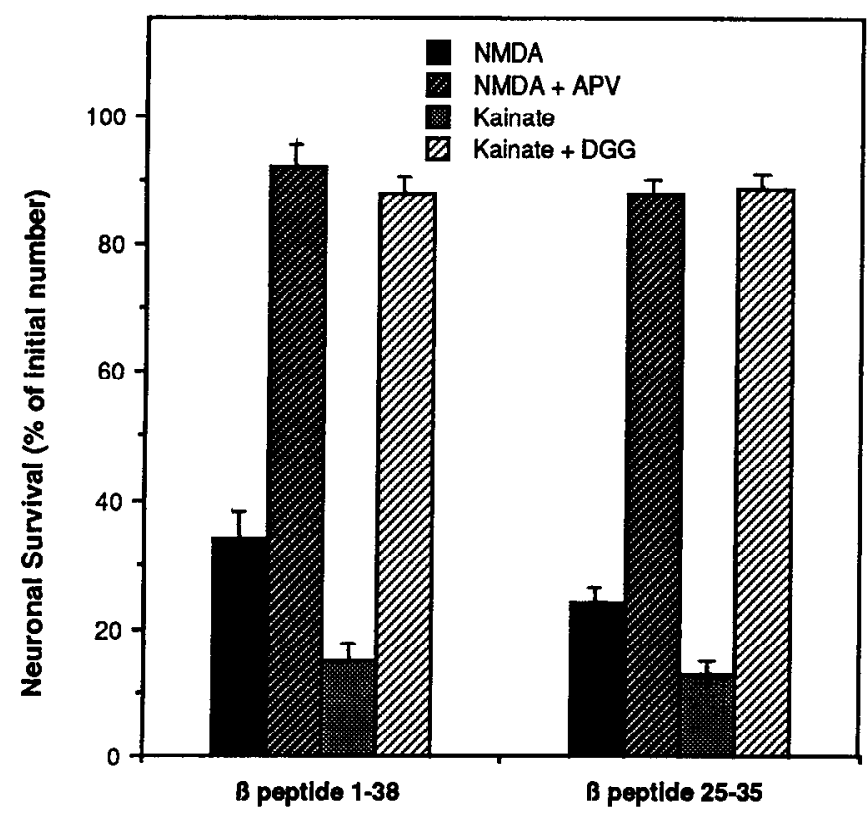

Figure 6. Glutamate receptor antagonists prevent the neuronal degeneration caused by coexposure to glutamate agonists and $\beta$ APs. Cortical cultures were exposed for $2 \mathrm{~d}$ to the indicated treatments ( $\beta \mathrm{APs}$ were diluted from aqueous stocks). $N M D A, 500 \mu \mathrm{M} ; A P V, 500 \mu \mathrm{M}$; Kainate, $200 \mu \mathrm{M} ; D G G, 500 \mu \mathrm{M}$. Values are the mean and SEM of determinations made in four separate cultures. Neuronal survival in cultures treated glutamate antagonists was significantly greater than in cultures lacking an antagonist $(p<0.001)$.

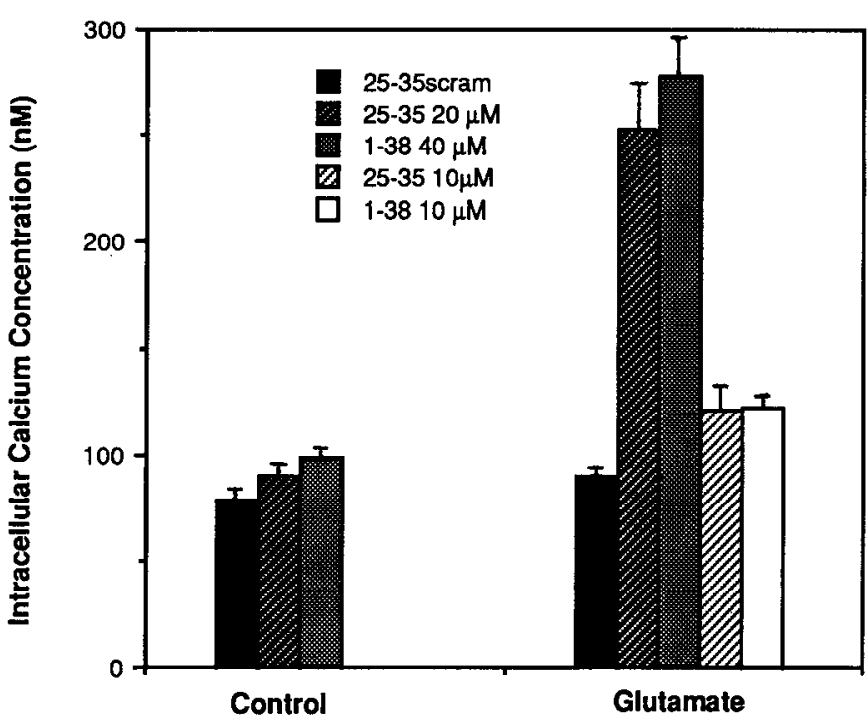

Figure 7. $\beta$ APs render human cortical neurons more vulnerable to glutamate-induced loss of calcium homeostasis. Intracellular free calcium levels were measured using fura- 2 in cultured cortical neurons that had been exposed for $2 \mathrm{~d}$ to the indicated peptides in the absence or presence of $500 \mu \mathrm{M}$ glutamate ( $\beta \mathrm{APs}$ were diluted from aqueous stocks). Values represent the mean and SEM of determinations made in from 11 to 20 neurons. Calcium levels in neurons treated with glutamate plus $20 \mu \mathrm{M} \beta \mathrm{AP} 25-35$ or $40 \mu \mathrm{M} \beta \mathrm{AP} 1-38$ were significantly greater than in neurons exposed to any of the other treatments $(p<$ $0.001)$.

dium was chosen since preliminary studies demonstrated that longer incubations in the calcium-deficient medium resulted in neuronal loss. Neurons incubated in the calcium-deficient medium were protected against the neurotoxicity of combined exposure to $\beta$ AP and glutamate (Fig. 8). Thus, calcium influx was necessary for the neuronal damage elicited by combined exposure to $\beta$ APs and glutamate.

$\beta A P$ s enhance calcium ionophore neurotoxicity. In order to better define the mechanism whereby $\beta$ APs potentiated EAAinduced elevations in intracellular calcium and cell death, we examined the effects of $\beta$ APs on calcium ionophore neurotoxicity. Cortical cell cultures that had been maintained for $3 \mathrm{~d}$ in the presence of $\beta$ APs or control peptide ( $5 \mu \mathrm{M}$ from a DMSO stock) were exposed to calcium ionophore A23187 (500 nM to $5 \mu \mathrm{M}$ ), and neuronal survival was assessed $4 \mathrm{hr}$ later. Neuronal vulnerability to A23187 was significantly enhanced by $\beta$ APs $25-35$ and 1-38 (Fig. 9). The $\beta$ APs shifted the dose-response curve to the left such that whereas $1 \mu \mathrm{M}$ A23187 killed only $20 \%$ of the neurons in control cultures, nearly $70 \%$ of the neurons were killed by this level of A23187 in cultures pretreated with $\beta$ AP $25-35$ or $1-38$.

$\beta A P s$ cause an elevation in intracellular calcium levels and enhance calcium responses to depolarization and calcium ionophore. Although rest levels of intraneuronal calcium were not significantly elevated after $2 \mathrm{~d}$ of treatment with $\beta$ APs (cf. Fig. 7 ), more prolonged treatment did result in a significant elevation in calcium levels. Intracellular free calcium levels were significantly elevated in neurons exposed to $\beta$ AP $25-35$ or $1-38$ (2 $\mu \mathrm{M}$ from DMSO stock) for $4 \mathrm{~d}$ when compared to neurons exposed to control peptide (Fig. 10). Calcium elevations in response to $\mathrm{K}^{+}$and $\mathrm{A} 23187$ were enhanced in neurons exposed to $\beta$ APs for $4 \mathrm{~d}$. Whereas neurons in control cultures showed essentially no calcium response to $46 \mathrm{mM} \mathrm{K}^{+}$, neurons in cultures pretreated with $\beta$ AP $1-38$ or $25-35$ ( $2 \mu \mathrm{M}$ from DMSO stock) 


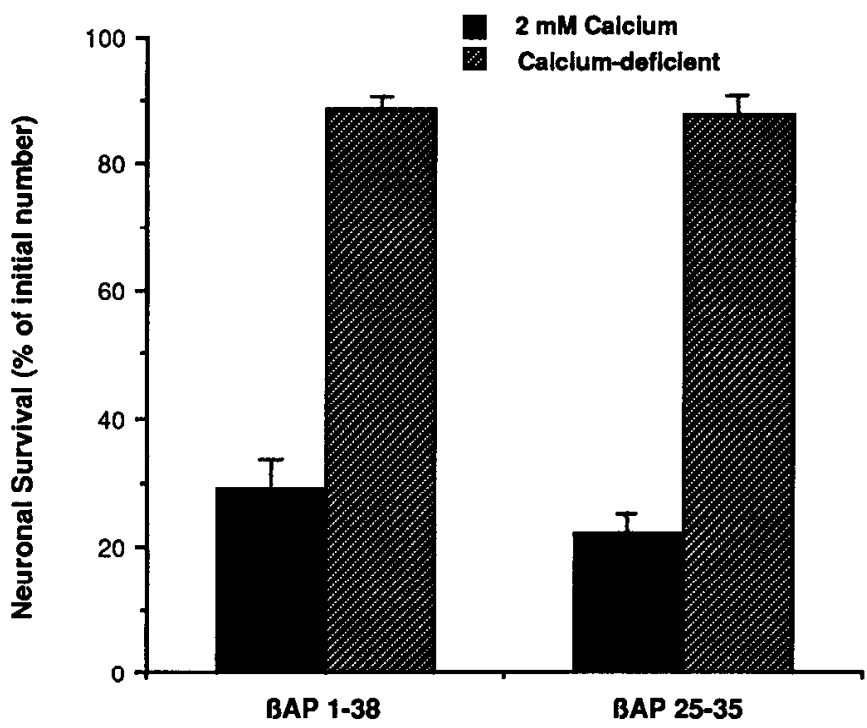

Figure 8. Neurotoxicity of combined exposure to $\beta$ APs and glutamate is dependent upon calcium influx. Cultures were exposed to $\beta$ AP $1-38$ or 25-35 ( $40 \mu \mathrm{M}$ from an aqueous stock) for $2 \mathrm{~d}$ in the normal culture medium, after which the culture medium was replaced with either calcium-containing or calcium-deficient medium (see Materials and Methods). $\beta$ APs and glutamate $(500 \mu \mathrm{M})$ were then added to the cultures, and neuronal survival was assessed $24 \mathrm{hr}$ later. Values represent the mean and SEM of determinations made in four separate cultures. Neuronal survival was significantly greater in cortical cultures exposed to a $\beta$ AP and glutamate in calcium-deficient medium than in calcium-containing medium $(p<0.001)$.

showed calcium rises of approximately $20 \mathrm{~nm}$. The calciumdestabilizing effect of $\beta$ APs was quite striking when the neurons were challenged with A23187 (1 $\mu \mathrm{M})$. Intracellular calcium levels in $\beta$ AP-treated cultures rose to $300-400 \mathrm{nM}$, versus $120-140$ nM in cultures exposed to control peptide $(p<0.001$; Fig. 10$)$. Similar results were obtained in a separate experiment in which cultures were exposed to $\mathrm{A} 23187$ without prior exposure to $\mathrm{K}^{+}$ (data not shown). Taken together, these data indicated that neurons exposed to $\beta A P$ s are compromised in their ability to regulate intracellular free calcium levels.

$N F T$-like antigenic changes and $\beta A P S$. We previously reported that EAAs and calcium influx can elicit antigenic changes in cultured rat and human central neurons similar to those seen in AD NFTs (Mattson, 1990; Mattson et al., 1991 h). NFTs are strongly reactive with antibodies to the microtubule-associated protein tau (Grundke-Iqbal et al., 1986; Nukina et al., 1987; Kosik et al., 1988) and ubiquitin (Mori et al., 1987; Perry et al., 1987). Human cortical cultures that had been exposed to $\beta A P s$, glutamate, or both $\beta$ APs and glutamate for $3 \mathrm{~d}$ were immunostained with tau antibody 5E2 (Kosik et al., 1988), Alz50 (Wolozin et al., 1986), or ubiquitin antiserum (Sigma). Neurons in untreated control cultures, cultures treated with scrambled $\beta \mathrm{AP}$, or cultures treated with $\beta \mathrm{AP} 1-38$ or $25-35$ alone showed only weak immunoreactivity with the three different antibodies (Table 1, Fig. $11 A, B$ ). Exposure of cultures to $\beta$ AP $1-38$ or $25-35$ alone resulted in no detectable effect on tau or ubiquitin immunoreactivities. Glutamate alone ( $1 \mathrm{~mm}$ ) elicited a small increase in neuronal immunorcactivity toward cach of the three antibodies (Table 1, Fig. 11C). Combined exposure to both a $\beta$-peptide and glutamate caused a marked increase in neuronal immunoreactivities (above that seen with glutamate alone) toward all three antibodies (Table 1, Fig. 11D).

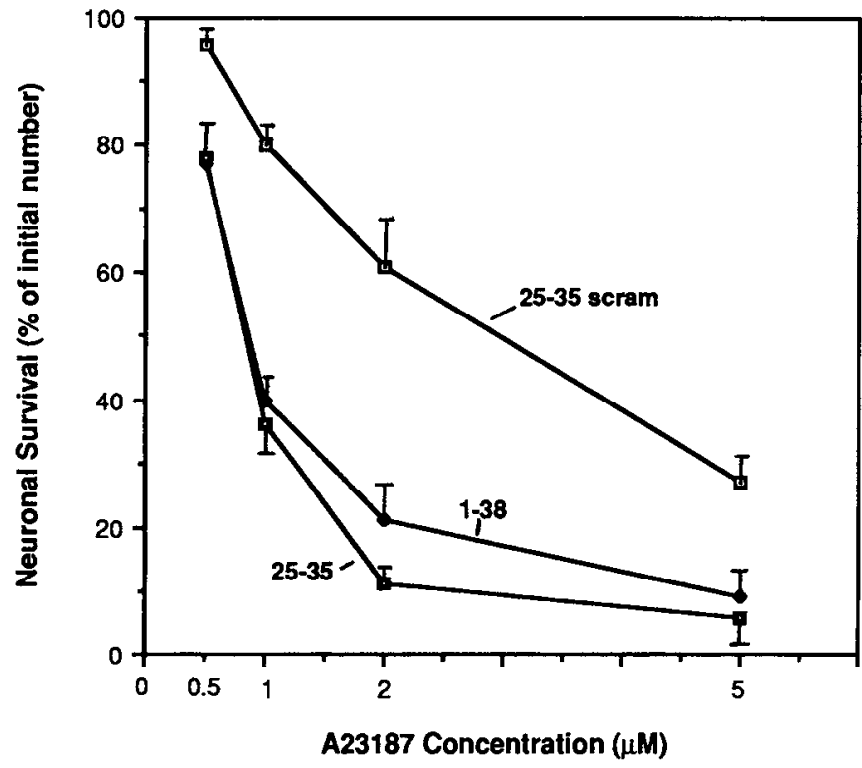

Figure 9. $\beta$ APs potentiate calcium ionophore neurotoxicity. Cortical cultures were maintained for $3 \mathrm{~d}$ in the presence of the indicated $\beta$ APs (5 $\mu \mathrm{M}$ 25-35scrambled, $\beta$ AP 1-38, or $\beta$ AP $25-35$; diluted from stocks in DMSO). Cultures were then exposed to calcium ionophore A23187 for $4 \mathrm{hr}$, and the percentage of neurons that survived the exposure to A23187 was determined. Values represent the mean and SEM of determinations made in four separate cultures.

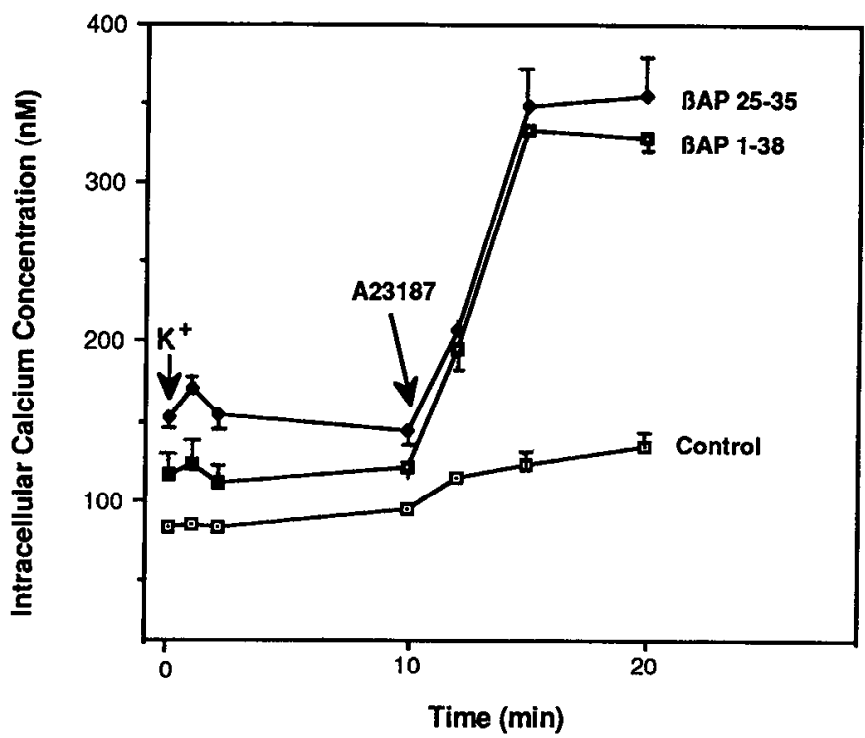

Figure 10. Effects of exposure to $\beta$ APs on rest levels of intracellular calcium and acute calcium responses to depolarization and calcium ionophore. Cortical cultures were exposed for $4 \mathrm{~d}$ to $2 \mu \mathrm{M}$ concentrations (diluted from stocks in DMSO) of the indicated peptides (control was scrambled $\beta$ AP 25-35). The cells were then loaded with fura-2, and cells were imaged prior to (time 0 ) and at the indicated time points following exposures to $\mathrm{K}^{+}(46 \mathrm{mM})$ and $\mathrm{A} 23187(1 \mu \mathrm{M})$, which were added at the times indicated by the arrows. Values represent intracellular free calcium levels in individual neurons (mean and SEM; $n=5-8$ ). Rest levels of intracellular calcium were significantly greater in neurons exposed to $\beta$ AP $25-35$ or 1-38 than in neurons in control cultures ( $p$ $<0.05$ ). Calcium levels at 2,5 , and $10 \mathrm{~min}$ following exposure to A23187 were significantly greater in $\beta$ AP-treated cultures than in control cultures $(p<0.001)$. 

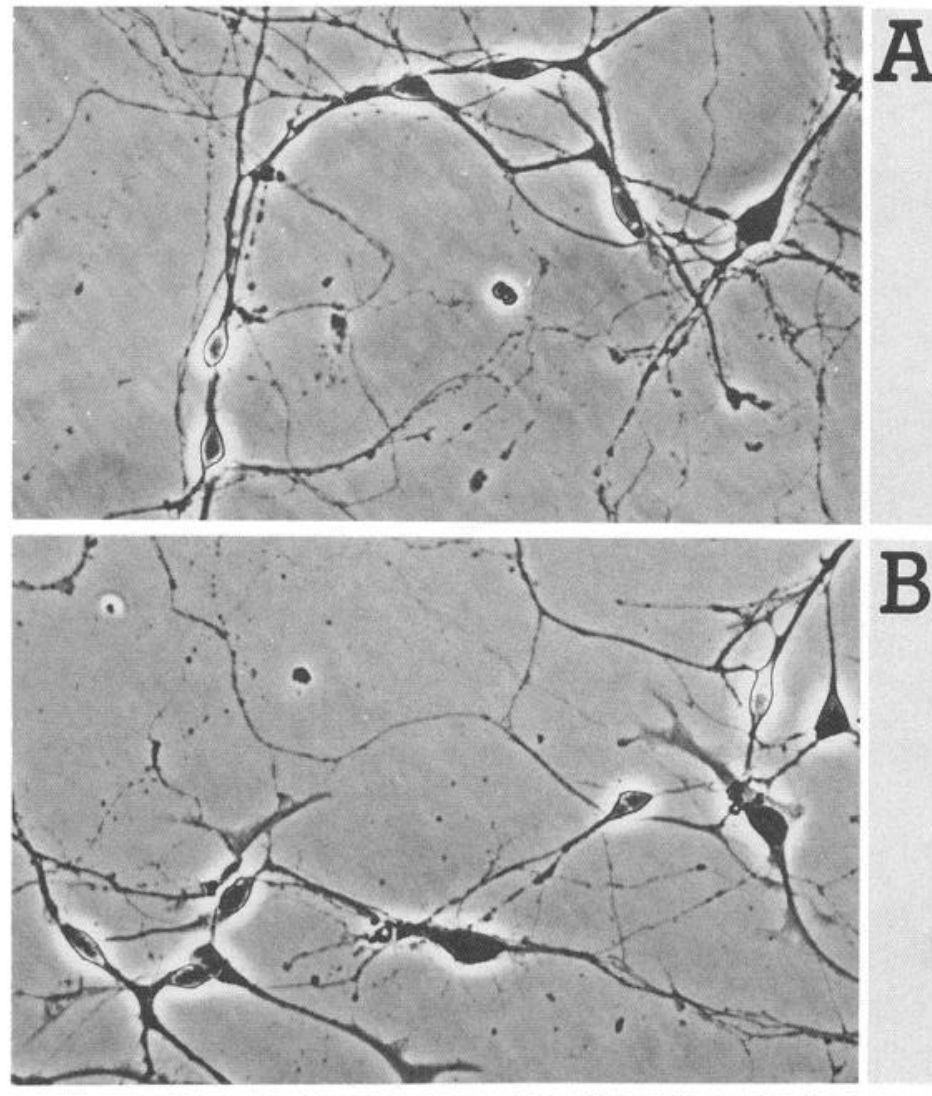

\section{B}

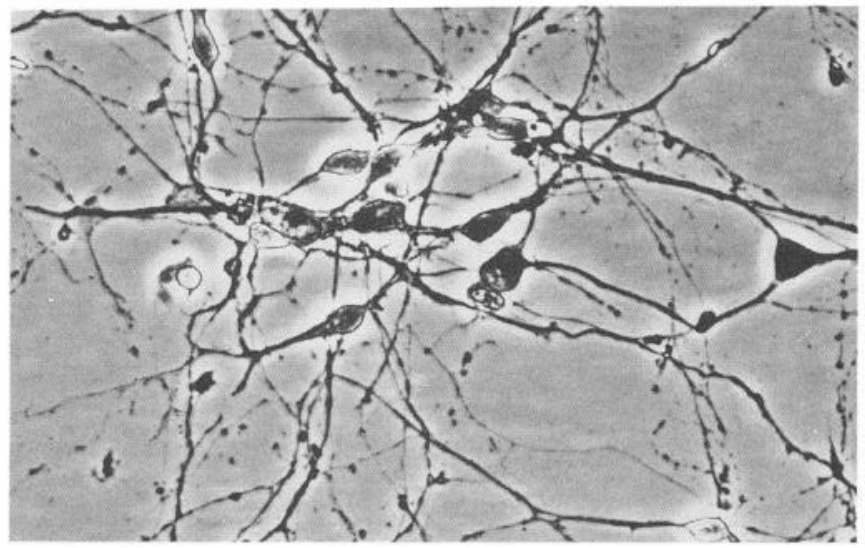

C 1
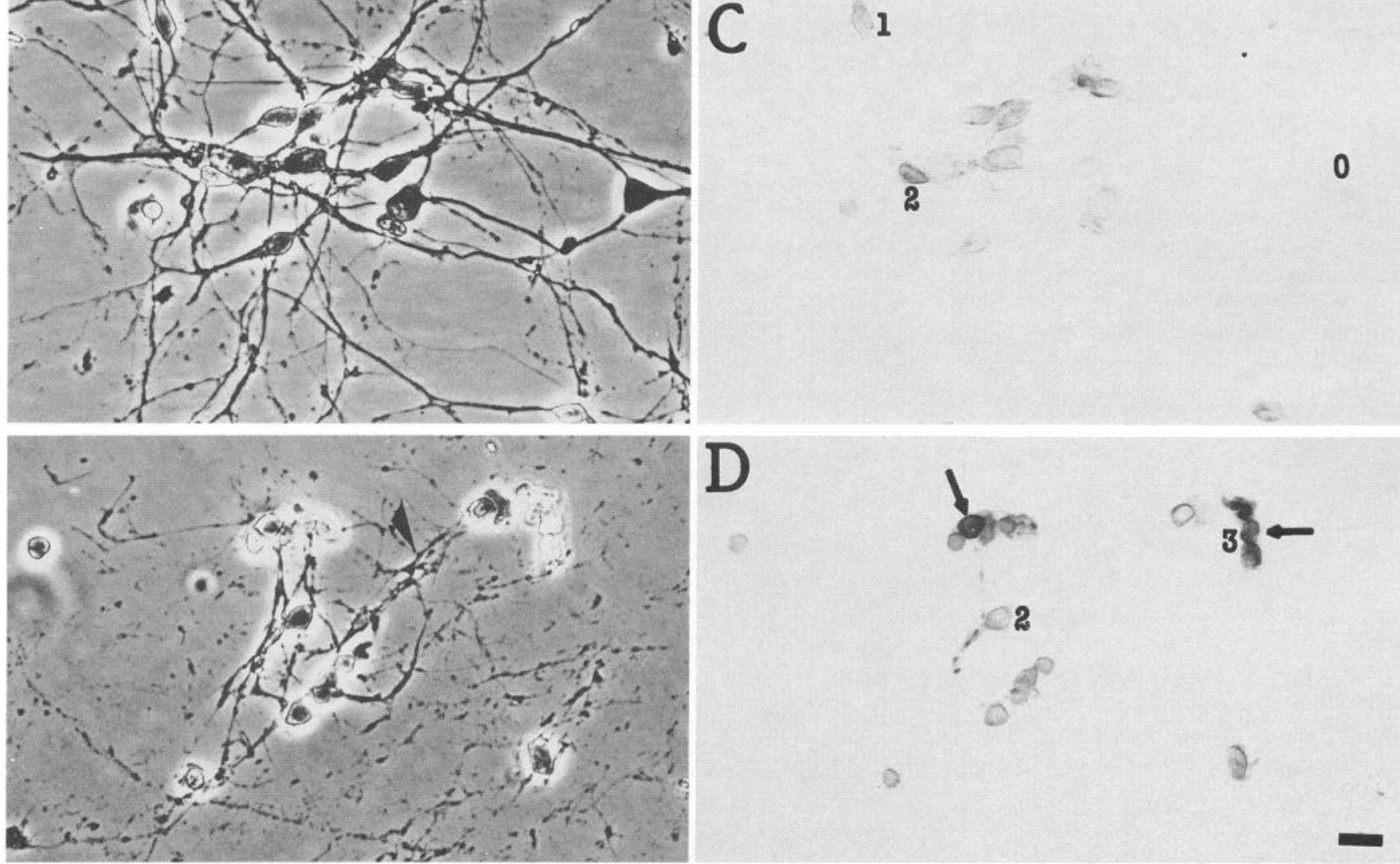

D

1

Eos.

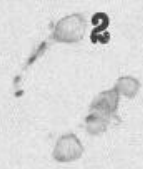

Figure 11. $\beta$ APs render human cortical neurons more vulnerable to NFT-like antigenic changes associated with glutamate neurotoxicity. Each panel $(A-D)$ consists of phase-contrast (left) and bright-field $(r i g h t)$ micrographs of cortical cultures immunochemically stained with tau antibody 5E2. $A, 3 \mathrm{~d}$ following exposure to $20 \mu \mathrm{M}$ scrambled $\beta$ AP $25-35 ; B, 3 \mathrm{~d}$ following exposure to $20 \mu \mathrm{M} \beta \mathrm{AP} 25-35 ; C, 3 \mathrm{~d}$ following exposure to 1 mM glutamate; $D, 3$ d following exposure to $20 \mu \mathrm{M} \beta \mathrm{AP} 25-35$ plus $1 \mathrm{mM}$ glutamate; note that neurons have degenerated (arrowhead points to 

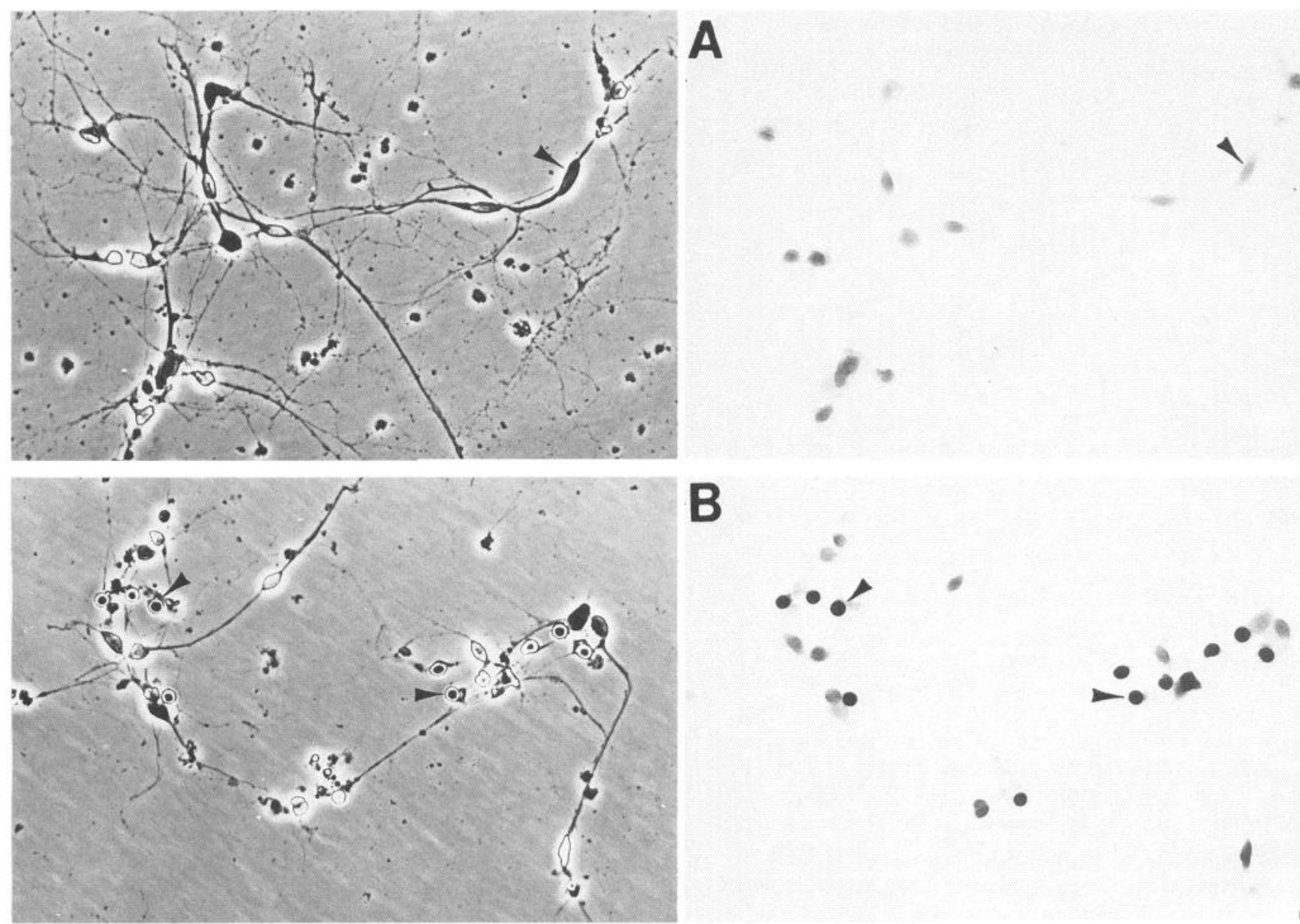

Figure 12. $\quad \beta$ APs render human cortical neurons more vulnerable to calcium ionophore-induced NFT-like antigenic changes. Each panel consists of phase-contrast (left) and bright-field (right) micrographs of cells immunocytochemically stained with ubiquitin antiserum. The cultures were exposed to $5 \mu \mathrm{M}$ concentrations of either control $\beta$ AP (25-35scrambled; $A$ ) or $\beta$ AP 1-38 $(B)$ for 2 d ( $\beta$ APs were diluted from DMSO stocks). The cultures were then exposed to $1 \mu \mathrm{M}$ calcium ionophore A23187 for $4 \mathrm{hr}$ and processed for ubiquitin staining. Ubiquitin immunoreactivity is considerably greater in neurons that had been exposed to $\beta$ AP 1-38 $(B)$ than in neurons in the control culture $(A)$. The neurons that stain intensely (e.g., arrowheads in $B$ ) have degenerated; (note loss of neurites), whereas the neurons that stain lightly appear healthy (e.g., arrowheads in $A$ ). Scale bar, $10 \mu \mathrm{M}$.

$\beta$ APs also induced increased staining with tau and ubiquitin antibodies in neurons exposed to calcium ionophore A23187. For example, when cortical cultures were exposed to $1 \mu \mathrm{M}$ A23187 for $4 \mathrm{hr}$, the number of neurons with strong ubiquitin immunoreactivity was markedly increased in neurons that had been pretreated for $2 \mathrm{~d}$ with $\beta$ AP $25-35$ or 1-38 (Table 1, Fig. 12). Thus, $\beta$ APs can make neurons more vulnerable to changes occurring in degenerating neurons resulting from a loss of neuronal calcium homeostasis.

\section{Discussion}

The present findings demonstrate that $\beta$ APs render human cortical neurons more vulnerable to calcium influx and EAA neurotoxicity, suggesting that the $\beta$ APs destabilize calcium homeostasis. The data obtained in this study are consistent with the possibility that $\beta$-amyloid plays an active role in the neurode- generation that occurs in $\mathrm{AD}$, as has been previously hypothesized. Past studies in animal systems indicated that $\beta$-amyloid (Yankner et al., 1990; Koh et al., 1990a), and perhaps other regions of the APP (Yankner et al., 1989), can be neurotoxic. Conditioned medium taken from PC12 cells or fibroblasts transfected with a portion of the APP gene containing the C-terminal region was toxic to rat hippocampal neurons in cell culture (Yankner et al., 1989). However, medium taken from cells expressing the $\beta$-amyloid protein alone was not neurotoxic in the latter study. More recently, Yankner et al. (1990) reported that synthetic $\beta$ APs $1-38,1-40$, and $25-35$ were neurotoxic in rat hippocampal cultures. Koh et al. (1990a) reported that while $\beta$ AP $1-42$ was not by itself neurotoxic in mouse cortical cell cultures, it did render neurons more vulnerable to EAA neurotoxicity. We also did not find that $\beta$ APs were, by themselves, neurotoxic in the cultured human cortical neurons.

fragmented neurites). For these experiments, peptides were diluted from aqueous stocks. Note that neurons stain more intensely in cultures exposed to both the $\beta \mathrm{AP}$ and glutamate (e.g., arrows), than in cultures exposed to either the peptide or glutamate alone. Numbers adjacent to neurons indicate the relative staining intensity of that neuron on a scale from 0 to 3 ( 0 , no staining; 1 , low; 2 , moderate, 3 , intense). Scale bar, $10 \mu \mathrm{M}$. 
Table 1. Effects of $\beta \Lambda P s$, glutamate, and calcium ionophore on neuronal immunoreactivity toward tau and ubiquitin antibodies in human cortical cell cultures

\begin{tabular}{llll} 
& \multicolumn{3}{l}{ Average staining intensity } \\
\cline { 2 - 4 } Treatment & $5 \mathrm{E} 2$ & Alz-50 & $\begin{array}{l}\text { Ubi- } \\
\text { quitin }\end{array}$ \\
\hline Control & 0.5 & 0.5 & 1.2 \\
$\beta A P ~ 1-38(40 \mu \mathrm{M})$ & 0.7 & 0.6 & 1.0 \\
$\beta$ AP 25-35 $(20 \mu \mathrm{M})$ & 0.8 & 0.5 & 1.1 \\
Glutamate $(1 \mathrm{mM})$ & 1.1 & 0.9 & 1.5 \\
$\beta$ AP 1-38 + glutamate & 2.1 & 1.6 & 2.0 \\
$\beta$ AP 25-35 + glutamate & 2.0 & 1.9 & 2.0 \\
A23187 $(1 \mu \mathrm{M})$ & 1.2 & 1.2 & 1.3 \\
$\beta$ AP 1-38 + A23187 & 2.3 & 1.9 & 2.0 \\
$\beta$ AP 25-35 + A23187 & 2.2 & 2.0 & 2.3
\end{tabular}

Human cortical cell cultures were exposed for $3 \mathrm{~d}$ to no treatment (Control), a $\beta \mathrm{AP}$ (diluted from an aqueous stock), glutamate, or a $\beta \mathrm{AP}$ plus glutamate as indicated. Another set of cultures were or were not pretreated for $3 \mathrm{~d}$ with a $\beta A P$ and were then exposed to calcium ionophore A23187 for $4 \mathrm{hr}$. The cells were then fixed and immunochemically stained with a tau antibody ( $5 \mathrm{E} 2$ or $\mathrm{Alz}-50$ ) or with anti-ubiquitin. The staining intensity of individual neurons was then scored on a scale from 0 to 3 (0, no staining; 1 , low; 2, moderate; 3, intense; cf. Fig. 11). Each value represents the average staining intensity of a total of 300 neurons scored in three separate cultures (100 neurons/culture)

There are several possible explanations for the direct neurotoxic actions of $\beta$ APs reported by Yankner et al. (1989, 1990) on the one hand, and the lack of effect of $\beta A P s$ alone in our study and that of Koh et al. (1990a) on the other hand. The different studies utilized cell cultures derived from different species and different brain regions, leaving open the possibilities that neurons from different species or brain regions are differentially vulnerable to $\beta$-amyloid. We have previously reported that human cortical neurons are inherently different than rat cortical neurons in their rates of development and survival in cell culture (Mattson and Rychlik, 1991). In addition, development of calcium and neurotoxic responses to glutamate is significantly slower in the human neurons (Mattson et al., 199 1a). Interestingly, we have recently found that $\beta$ APs act to destabilize calcium homeostasis more rapidly (i.e., elevated rest levels of calcium and enhanced responses to glutamate) in rat hippocampal neurons than in human cortical neurons (M. P. Mattson and R. E. Rydel, unpublished observations). Work is in progress to determine whether more prolonged exposure of human neurons to $\beta$ APs (weeks) will cause neuronal death. Whether neurons from different brain regions and different types of neurons within a brain region are differentially vulnerable to $\beta A P$ s remains to be determined. However, our data and that of Yankner et al. (1990) suggest that different neurons within the hippocampal and cortical populations are differentially sensitive to $\beta \mathrm{AP}$ neurotoxicity. Thus, all neurons were not equally vulnerable to direct $\beta$-amyloid neurotoxicity or $\beta$ AP enhancement of glutamate neurotoxicity. In addition, the cytotoxic actions of $\beta$-amyloid may be specific for neurons since astrocytes were not killed by $\beta$ APs (Yankner et al., 1989, 1990; present results). Clearly, understanding the cell specificity of $\beta$-amyloid's actions on intracellular calcium and cell survival will shed light on the mechanism of $\beta \mathrm{AP}$ neurotoxicity and its role in $\mathrm{AD}$.

Culture conditions may also be important in determining whether neurons are vulnerable to $\beta$-amyloid. For example, the cultures of Koh et al. (1990) were maintained in serum-free medium, while those of Yankner (1990) were maintained in serum-containing medium. Since Yankner et al. (1990) employed serum-containing medium and also supplemented this with 5\% Ham's F12 medium, which contains glutamate, it seems likely that there were quite high levels of glutamate in that medium (approximately 15-20 $\mu \mathrm{M}$ glutamate with serum and HAM's supplements). Therefore, it may have been the case that what was presumed to be a neurotoxic action of $\beta$ APs alone might actually have been a rendering of the neurons more vulnerable to the neurotoxicity of ambient levels of glutamate in the culture medium. In any case, the available data suggest that environmental factors may determine whether a neuron is or is not vulnerable to $\beta$-amyloid toxicity.

$\beta$ APs enhanced both kainate and NMDA neurotoxicities in the cultured human cortical neurons, and the neuronal degencration could be prevented by appropriatc glutamatc reccptor antagonists. We interpret these data to indicate the involvement of the normal glutamate receptor-activated excitotoxic pathway in mediating the neuronal degeneration. This possibility is further suggested by the observation that kainate and NMDA were more potent than glutamate in inducing neuronal death in the present study. These data are similar to previous observations on the neurotoxic potencies of these different agonists (see Coyle et al., 1981; Choi, 1988). However, since glutamate (but not kainate and NMDA) is actively taken up by brain cells, we cannot rule out the possibility that the lesser potency of glutamate was due to a decreased extracellular concentration with time in culture.

Choi (1987) previously described two forms of glutamate neurotoxicity, an "early" or rapid form that occurred within hours and was calcium independent, and a "late" or slow form that required many hours to days and was calcium dependent. Clcarly, the toxicity examined in the present study fits into the late or slow category as it occurred over a period of days and was calcium dependent. Interestingly, the excitotoxicity-potentiating effect of $\beta$ APs required a relatively long exposure to the peptides. When human cortical cultures were pretreated for several days with the $\beta$ APs prior to the addition of glutamate, subsequent excitotoxic damage was much more rapid than when the $\beta A P s$ and glutamate were added to the cultures simultaneously. Similar results were obtained by Koh et al. (1990) in mouse cortical cell cultures, where there was a direct relationship between the duration of pretreatment with $\beta \mathrm{AP} 1-42$ and the extent of neuronal damage $24 \mathrm{hr}$ following exposure to NMDA. Since $\beta A P$-enhanced excitotoxicity resulted from a destabilization of calcium homeostasis, these findings suggest that $\beta$-amyloid affects calcium homeostasis by a process requiring considerable time.

Although the mechanism whereby $\beta$ APs destabilize calcium homeostasis is not known, several possibilities are worth considering. $\beta$ APs may have relatively nonspecific effects on, for example, cellular energy regulation or defense mechanisms against free radical damage since neurons with a compromised energy supply are more vulnerable to excitotoxicity. The present data suggest that specific neuronal systems for calcium homeostasis might also be more direct targets for the actions of $\beta$-amyloid. For example, $\beta$-amyloid might enhance calcium influx by influencing voltage- or EAA-gated channels, or systems for calcium buffering might be affected by $\beta$-amyloid. The fact that the $\beta$ APs rendered human cortical neurons more vulnerable to calcium ionophore indicates that at least part of the action of these peptides is to compromise the ability of the neuron to reduce calcium levels following a challenge. Neurons possess 
several different means to reduce intracellular free calcium levels, the most notable being the plasma membrance $\mathrm{Ca}^{2+}$ ATPase and $\mathrm{Na}^{+} / \mathrm{Ca}^{2+}$ exchanger, and calcium-binding proteins (Carofoli, 1987). Previous data obtained in studies of cultured rat hippocampal neurons indicated that two of these buffering systems, the $\mathrm{Na}^{+} / \mathrm{Ca}^{2+}$ exchanger and the $28 \mathrm{kDa}$ calcium-binding protein calbindin, protect neurons against EAA toxicity (Mattson et al., 1989b, 1991c). Alterations in neuronal $\mathrm{Na}^{+} / \mathrm{Ca}^{2+}$ exchange in AD have been reported (Colvin et al., 1991). The possibility that $\beta$-amyloid affects the expression or function of proteins involved in neuronal calcium homeostasis is now being examined.

$\beta$-amyloid is quite insoluble in physiological salt solutions, a property that likely contributes to its accumulation in plaques. An important issue concerning the role of $\beta$-amyloid in AD is whether aggregation is required for biological activity. We chose to examine the effects of peptide stocks made up in both water and DMSO. The solvent greatly affected the dose-response curve for $\beta \mathrm{AP}$ enhancement of glutamate neurotoxicity. When DMSO was used to increase peptide solubility, biological activity was enhanced approximately 100 -fold such that activity was seen in the concentration range of 10-100 nM. These effective concentrations are similar to those observed by Yankner et al. (1990) in hippocampal neurons, where $\beta$ APs were solubilized in $35 \%$ acetonitrile and $0.1 \%$ TFA. Interestingly, we observed that $\beta A P$ 25-35 was more potent than $\beta$ AP 1-38 when these peptides were dissolved in water, and this differential potency was eliminated when the peptides were dissolved in DMSO. Preliminary gel filtration studies utilizing physiological salt solutions indicate that in the soluble fraction $\beta \mathrm{AP} 1-38$ and $\beta \mathrm{AP} 25-35$ predominate as dimer and tetramer complexes, respectively. The inclusion of DMSO appears to stabilize the monomer forms of both peptides (A. Culwell, V. John, and R. E. Rydel, unpublished observations). These findings are consistent with the possibility that the $\beta$ APs are biologically active in a soluble state. Whether the peptides are active as monomers or complexes remains to be established. Interestingly, recent data suggest that $\beta$-amyloid is not insoluble in aqueous solutions to the extent previously suggested. It is becoming increasingly clear that the solubility of $\beta$-amyloid is quite sensitive to conditions such as pH (Barrow and Zagorski, 1991) and ionic strength (Hilbich et al., 1991) such that the $\beta$-amyloid may exist as monomers or aggregates with different conformations (random coil, $\beta$-sheet, or $\alpha$-helical structures). A full understanding of if and how these different forms of $\beta$-amyloid influence biological activity, and how this relates to the pathology of $\mathrm{AD}$, will clearly require considerable further work.

It is not clear how the concentrations of the peptides in the solutions of the present study relate to the normal conditions in vivo. Since $\beta$-amyloid is insoluble and aggregates extracellularly (Klier et al., 1990), it might be expected that its actions in vivo occur quite locally. This possibility is certainly consistent with the observations that degenerated neurons and neurites are often apposed to amyloid deposits in AD (Selkoe, 1989; Bugiani et al., 1990) and that $\beta$-amyloid may also accumulate within degenerating neurons (Hyman et al., 1989). In addition, Spillantini et al. (1990a,b) have provided evidence that $\beta$-amyloid undergoes changes in its configurational state as the amyloid aggregates and plaques mature. Their data suggest that abnormal processing of the $\beta$-amyloid precursor may occur within neurons that are in the early stages of NFT formation. Perhaps such a local deposition of $\beta$-amyloid and its association with the neu- ronal surface render that neuron more vulnerable to environmental factors such as EAAs that tend to cause a loss of calcium homeostasis and neuronal degeneration.

At this point, it is not clear whether there are cell-surface receptors that mediate the calcium-destabilizing actions of $\beta$ APs, or whether the peptide's actions occur by less specific actions at the membrane or within the cell. Biological activity within the 10-100 nM range (Fig. 4; Yankner et al., 1990) is consistent with action at a receptor. It is interesting that the neurotoxic activity of $\beta$-amyloid resides within amino acids $25-35$. This stretch of amino acids has a high degree of homology to the tachykinin neuropeptide family, and Yankner et al. (1990) found that tachykinin antagonists were neurotoxic to cultured rat hippocampal neurons and that the tachykinin agonist substance $P$ prevented $\beta$-amyloid neurotoxicity. However, recent binding studies indicate that $\beta$-amyloid does not compete for substance $P$ receptors but does bind specifically to serine protease inhibitor receptors (Joslin et al., 1991). Interestingly, Koh et al. (1990) reported that both $\beta$ APs $1-42$ and $1-28$ potentiated glutamate neurotoxicity. Taken together with Yankner's data (1990), these results suggest that the four amino acid stretch from residues 25 to 28 (GSNK) in the $\beta$-peptide might have biological activity. In addition to possible receptor-mediated actions of the $\beta$ APs, actions within the cell should also be considered since there is precedence for intracellular sites of action of highly insoluble neurotoxic proteins; a case in point is the scrapie prion protein (Prusiner, 1989). It is not known whether $\beta$-amyloid is taken up by neurons, but the observations that the precursor protein accumulates in neuronal lysosomes (Benowitz et al., 1989) and that amyloid deposits contain lysosomal proteases (Cataldo and Nixon, 1990) are consistent with an uptake process.

We previously found that EAAs and calcium influx could elicit antigenic changes in cultured rat and human central neurons similar to those seen in NFTs in AD and related disorders (Mattson, 1990; Mattson et al., 1991b). In the present study, we found that $\beta$-amyloid enhanced the appearance of NFT-like antigenic changes in human cortical neurons exposed to EAAs or calcium ionophore. Our previous studies (Mattson, 1990; Mattson et al., 1991b) and those of others (Ueda et al., 1990) indicated that the alterations in tau result from calcium-mediated phosphorylation and disruption of microtubules. The increased ubiquitin immunoreactivity is considered a rather nonspecific response in degenerating neurons. Our past studies of calcium-induced cytoskeletal alterations in cultured neurons revealed many of the alterations observed in AD NFTs (e.g., loss of microtubules, accumulation of straight filaments, tau abberations), but paired helical filaments were not observed (Mattson et al., 1991b). In light of the recent evidence indicating that $\beta$-amyloid may be associated with NFTs (Hyman et al., 1989; Spillantini et al., 1990a,b), it would seem useful to examine further the hypothesis that $\beta$-amyloid plays a role in paired helical filament formation.

Finally, it is useful to consider how the present data might relate to the pathophysiology of $\mathrm{AD}$ and related disorders. In general, neurons in the mammalian CNS lie in a precarious position with respect to calcium homeostasis. Calcium is utilized as a second messenger that mediates the adaptive processes of information coding and morphological plasticity. At the same time, the inability to maintain intracellular calcium levels within critical limits results in neuritic regression and cell death (Mattson, 1992). Calcium mediates the actions of many of the major intercellular signals in the nervous system. Neurons that are 
vulnerable in $\mathrm{AD}$ receive prominent glutamatergic input (Maragos et al., 1987) and also respond to trophic factors such as NGF and fibroblast growth factor (Hefti et al., 1984; Anderson et al., 1988; Mattson et al., 1989a). The balance between EAA and growth factor inputs is likely to be quite delicate in some neurons, and any alteration that upsets this balance is likely to have dire consequences. In $\mathrm{AD}$, the accumulation of $\beta$-amyloid may destabilize calcium homeostasis and so render neurons more vulnerable to other calcium-elevating agents such as EAAs. Agerelated changes (e.g., reduced perfusion, decline in trophic factor levels, endocrine abnormalities) may contribute to an increased vulnerability to $\beta$-amyloid. In some cases, specific genetic abnormalities may lead to amyloid deposition and neuronal degeneration, while in other cases environmental or functional aberrations might lead to a loss of calcium homeostasis and cell death. The calcium hypothesis of $\beta$-amyloid's role in AD may therefore apply to cases that result from mutations in the APP (Goate et al., 1991), as well as to late onset AD, which is certainly not a homogeneous disorder and likely results from multiple causes (St George-Hyslop et al., 1990).

\section{References}

Anderson KJ, Dam D, Lee S, Cotman CW (1988) Basic fibroblast growth factor prevents death of lesioned cholinergic neurons in vivo. Nature 332:360-361.

Barrow CJ, Zagorski MG (1991) Solution structures of $\beta$ peptide and its constituent fragments: relation to amyloid deposition. Science 253: 179-182.

Beal F, Kowall NW, Ellison DW, Mazurek MF, Swartz KJ, Martin JB (1986) Replication of the neurochemical characteristics of Huntington's disease by quinolinic acid. Nature 321:168-171.

Benowitz LI, Rodriguez W, Paskevich P, Mufson EJ, Schenk D, Neve RL (1989) The amyloid precursor protein is concentrated in neuronal lysosomes in normal and Alzheimer disease subjects. Exp Neurol 106:237-250.

Bugiani O, Giaccone G, Verga L, Pollo B, Ghetti B, Frangione B, Tagliavini F (1990) Alzheimer patients and Down patients: abnormal presynaptic terminals are related to cerebral preamyloid deposits. Neurosci Lett 119:56-59.

Carafoli E (1987) Intracellular calcium homeostasis. Annu Rev Biochem 56:395-433.

Cataldo AM, Nixon RA (1990) Enzymatically active lysosomal proteases are associated with amyloid deposits in Alzheimer brain. Proc Natl Acad Sci USA 87:3861-3865.

Choi DW (1987) Ionic dependence of glutamate neurotoxicity. J Neurosci 7:369-379.

Choi DW (1988) Glutamate neurotoxicity and diseases of the nervous system. Neuron 1:623-634.

Colvin RA, Bennett JW, Colvin SL, Allen RA, Martinez J, Miner GD (1991) $\mathrm{Na}^{+} / \mathrm{Ca}^{2+}$ exchange activity is increased in Alzheimer's disease brain tissues. Brain Res 543:139-147.

Coyle JT, Bird SJ, Evans RH, Gulley RL, Nadler JV, Nicklas WJ, Olney JW (1981) Excitatory amino acid neurotoxins: selectivity, specificity, and mechanisms of action. Neurosci Res Prog Bull 19:330-427.

Dyrks T, Weidemann A, Multhaup G, Salbaum JM, Lemaire H-G, Kang J, Muller-Hill B, Masters CL, Beyreuther K (1988) Identification, transmembrane orientation and biogenesis of the amyloid A4 precursor of Alzheimer's disease. EMBO J 7:949-957.

Esch FS, Keim PS, Beattie EC, Blacher RW, Culwell AR, Oltersdorf T, McClure D, Ward PJ (1990) Cleavage of amyloid $\beta$ peptide during constitutive processing of its precursor. Science 248:1122-1124.

Gibson GE, Peterson C (1987) Calcium and the aging nervous system. Neurobiol Aging 8:329-343.

Goate A, Chartier-Harlin M-C, Mullan M, Brown J, Crawford F, Fidani L, Gluffra L, Haynes A, Irving N, James L, Man R, Newton P, Rooke K, Roques P, Talbot C, Williamson R, Rossor M, Owen M, Hardy J (1991) Segregation of a missense mutation in the amyloid precursor protein gene with familial Alzheimer's disease. Nature 349: 704-707.
Grecnamyrc JT, Young AB (1989) Excitatory amino acids and Alzheimer's disease. Neurobiol Aging 10:593-602.

Grundke-Iqbal I, Iqbal K, Tung Y-C, Quinlan M, Wisniewski HM, Binder LI (1986) Abnormal phosphorylation of the microtubuleassociated protein tau in Alzheimer cytoskeletal pathology. Proc Natl Acad Sci USA 83:4913-4917.

Grynkiewicz G, Poenie M, Tsien RY (1985) A new generation of calcium indicators with greatly improved fluorescence properties. $\mathrm{J}$ Biol Chem 260:3440-3450.

Hefti F, Dravid A, Hartikka J (1984) Chronic intraventricular injections of nerve growth factor elevate hippocampal choline acetyltransferase activity in adult rats with partial sento-hippocampal lesions. Brain Res 293:305-311.

Hilbich C, Kisters-Woike B, Reed J, Masters CL, Beyreuther K (1991) Aggrcgation and sccondary structure of synthetic amyloid $\beta A 4$ peptides of Alzheimer's disease. J Mol Biol 218:149-163.

Hyman BT, Van Hoesen GW, Beyreuther K, Masters CL (1989) A4 amyloid protein immunoreactivity is present in Alzheimer's disease neurofibrillary tangles. Neurosci Lett 101:352-355.

Jones BN, Gilligan JP (1983) $o$-Phthaldialdehyde precolumn derivatization and reversed-phase high-performance liquid chromatography of polypeptide hydrolysates and physiological fluids. J Chromatogr 266:471-482.

Joslin G, Krause JE, Adams SP, Fallon RJ, Perlmutter DH (1991) Substance $\mathrm{P}$, bombesin and the amyloid $\beta$-protein compete with $\alpha_{1}$ AT antitrypsin-protease complexes for binding to the serpin-enzyme complex (SEC) receptors. J Biol Chem, in press.

Kang J, Lemaire H-G, Unterbeck A, Salbaum JM, Masters CL, Grzesckik K-H, Multhaup G, Beyreuther K, Muller-Hill B (1987) The precursor of Alzheimer's disease amyloid A4 protein resembles a cellsurface receptor. Nature 325:733-736.

Klier FG, Cole G, Stallcup W, Schubert D (1990) Amyloid $\beta$-protein precursor is associated with extracellular matrix. Brain Res 515:336342.

Koh J-Y, Yang LL, Cotman CW (1990a) $\beta$-Amyloid protein increases the vulnerability of cultured cortical neurons to excitotoxic damage. Brain Res 533:315-320.

Koh J, Yang LL, Cotman CW (1990b) $\beta$-amyloid protein increases neuronal vulnerability to excitotoxins in cortical culture. Soc Neurosci Abstr 16:786.

Kosik KS, Orecchi LD, Binder L, Trojanowski JQ, Lee VM-Y, Lee G (1988) Epitopes that span the tau molecule are shared with paired hclical filaments. Ncuron 1:817-825.

Love S, Saitoh T, Quijada S, Cole GM, Terry RD (1988) Alz-50, ubiquitin and tau immunoreactivity of neurofibrillary tangles, Pick bodies and Lewy bodies. J Neuropathol Exp Neurol 47:393-405.

Maragos WF, Greenamyre JT, Penney JB, Young AB (1987) Glutamate dysfunction in Alzheimer's disease: an hypothesis. Trends Neurosci 10:65-68.

Mattson MP (1990) Antigenic changes similar to those seen in neurofibrillary tangles are elicited by glutamate and calcium influx in cultured hippocampal neurons. Neuron 4:105-117.

Mattson MP (1992) Calcium as sculptor and destroyer of neural circuitry. Exp Gerontol, in press.

Mattson MP, Kater SB (1989) Development and selective neurodegeneration in cell cultures from different hippocampal regions. Brain Res 490:110-125.

Mattson MP, Rychlik B (1990) Cell culture of cryopreserved human fetal cerebral cortical and hippocampal neurons: neuronal development and responses to trophic factors. Brain Res 522:204-214.

Mattson MP, Rychlik B (1991) Comparison of rates of neuronal development and survival in human and rat cerebral cortical cell cultures. Mech Ageing Dev 60:171-187.

Mattson MP, Dou P, Kater SB (1988) Outgrowth-regulating actions of glutamate in isolated hippocampal pyramidal neurons. J Neurosci 8:2087-2100.

Mattson MP, Murrain M, Guthrie PB, Kater SB (1989a) Fibroblast growth factor and glutamate: opposing roles in the generation and degeneration of hippocampal neuroarchitecture. J Neurosci 9:37283740.

Mattson MP, Guthrie PB, Kater SB (1989b) A role for $\mathrm{Na}^{+}$-dependent $\mathrm{Ca}^{2+}$ extrusion in protection against neuronal excitotoxicity. FASEB J 3:2519-2526.

Mattson MP, Rychlik B, You J-S, Sisken JE (1991a) Sensitivity of cultured human embryonic cerebral cortical neurons to excitatory 
amino acid-induced calcium influx and neurotoxicity. Brain Res 542: 97-106.

Mattson MP, Engle MG, Rychlik B (1991b) Effects of elevated intracellular calcium levels on the cytoskeleton and tau in cultured human cerebral cortical neurons. Mol Chem Neuropathol 15:117-142.

Mattson MP, Rychlik B, Ching C, Christakos S (1991c) Evidence for calcium-reducing and excitoprotective roles for the calcium-binding protein calbindin- $\mathrm{D}_{28 \mathrm{k}}$ in cultured hippocampal neurons. Neuron 6: 41-51.

McKee AC, Kosik KS, Kennedy MB, Kowall NW (1990) Hippocampal neurons predisposed to neurofibrillary tangle formation are enriched in type II calcium/calmodulin-dependent protein kinase. J Neuropathol Exp Neurol 49:49-63.

Mori H, Kondo J, Ihara T (1987) Ubiquitin is a component of paired helical filaments in Alzheimer's disease. Science 235:1641-1644.

Nukina N, Kosik KS, Selkoe DJ (1987) Recognition of Alzheimer paired helical filaments by monoclonal neurofilament antibodies is due to cross reaction with tau protein. Proc Natl Acad Sci USA 84: 3415-3419.

Perry G, Friedman R, Shaw G, Chau B (1987) Ubiquitin is detected in neurofibrillary tangles and senile plaque neurites of Alzheimer's disease. Proc Natl Acad Sci USA 84:3030-3036.

Prusiner SB (1989) Scrapie prions. Annu Rev Microbiol 43:345-374

Selkoe DJ (1989) Biochemistry of altered brain proteins in Alzheimer's disease. Annu Rev Neurosci 12:463-490.

Siman R, Card JP, Davis LG (1990) Proteolytic processing of $\beta$-amyloid precursor by calpain 1. J Neurosci 10:2400-2411.

Sisodia SS, Koo EH, Beyreuther K, Unterbeck A (1990) Evidence that beta-amyloid protein in Alzheimer's disease is not derived by normal processing. Science 248:492-495.
Spillantini MG, Goedert M, Jakes R, Klug G (1990a) Different configurational states of $\beta$-amyloid and their distributions relative to plaques and tangles in Alzheimer disease. Proc Natl Acad Sci USA 87:3947-3951.

Spillantini MG, Goedert M, Jakes R, Klug G (1990b) Topographical relationship between $\beta$-amyloid and tau protein epitopes in tanglebearing cells in Alzheimer's disease. Proc Natl Acad Sci USA 87: 3952-3956.

St George-Hyslop PH, Haines JL, Farrer LA, Polinsky R, Van Broeckhovens C, Goate A, McLachlan DRC, Orr H, Bruni AC, Sorbi S, Rainero I, Foncin JF, Pollen D, Cantu JM, Tupler R, Voskresenskaya N, Maycux R, Growdon J, Fricd VA, Mycrs RH, Nec L, Backhovens H, Martins JJ, Rossor M, Owen MJ, Mullan M, Percy ME, Karlinsky H, Rich S, Heston L, Montesi M, Mortilla M, Nacmias N, Gusella JF, Hardy JA (1990) Genetic linkage studies suggest that Alzheimer's disease is not a single homogeneous disorder. Nature 347:194 197.

Ueda K, Masliah E, Saitoh T, Bakalis SL, Scoble H, Kosik KS (1990) Alz-50 recognizes a phosphorylated epitope in tau. J Neurosci 10: 3295-3304.

Wolozin BL, Pruchnicki A, Dickson DW, Davies P (1986) A neuronal antigen in the brains of Alzheimer's patients. Science 232:648-650.

Yankner BA, Dawes LR, Fisher S, Villa-Komaroff L, Oster-Granite M, Neve RL (1989) Neurotoxicity of a fragment of the amyloid precursor associated with Alzheimer's disease. Science 243:417-420.

Yankner BA, Duffy LK, Kirschner DA (1990) Neurotrophic and neurotoxic effects of amyloid $\beta$ protein: reversal by tachykinin neuropeptides. Science 250:279-282. 